\title{
Recent Developments on Pharmacological Potential of 1,3,4-0xadiazole Scaffold
}

\author{
Bhutani Rubina ${ }^{1, *}$, Pathak Dharam P1, Kapoor Garima', Kant Ravi', Dutta Manni² \\ ${ }^{1}$ Department of Pharmaceutical Chemistry, Delhi Institute of Pharmaceutical Sciences and Research, New Delhi, INDIA. \\ ${ }^{2}$ School of Medical and Allied Sciences, GD Goenka University, Gurgaon, Haryana, INDIA.
}

\begin{abstract}
Heterocyclic compounds represent the important structural key in pharmaceutical medicinal chemistry. In literature, five-membered heterocycles are reported to be a core moiety of various pharmaceutical drugs. 1,3,4-oxadiazole scaffold, among various five-membered heterocycles is an important molecule which attracts various medicinal chemist to develop a novel biologically active molecule. 1,3,4-Oxadiazole is found to bear important pharmacological activities such as anti-diabetic, antimicrobial, anti-cancer, anticonvulsant, antioxidant, anti-Alzheimer's, anti-inflammatory, antiviral, cardiovascular, anti-tuberculosis, anti-pyretic, insecticidal. This review compiles the biological updates on various compounds containing 1,3,4-oxadiazole as a core moiety from the recent years.

Key words: Anti-diabetic, Anti-cancer, Heterocycle, Oxadiazole, Pharmacological activity. Key messages: Five membered heterocyclic compounds are important in pharmaceutical chemistry. 1,3,4-oxadiazole scaffold possess diverse biological activities. Pharmacological activities shown by 1,3,4-oxadiazole derivatives include anti-diabetic, anticancer, antiinflammatory, antiviral, antimicrobial etc. It can be further explored as a lead molecule because of its role in various biological activities.
\end{abstract}

\section{INTRODUCTION}

Heterocyclic ring containing compounds are of great value both medicinally and industrially. ${ }^{1}$ Five-membered heterocycles demonstrated their efficacy in medicinal chemistry. Oxadiazole scaffold containing one oxygen and two nitrogen atoms in the five membered ring is a heterocyclic compound of great significance. Oxadiazole ring act as a pharmacophore in various clinically used number of drugs such as Raltegravir, Zibotentan, Furamizole. ${ }^{2,3}$ It is derived by replacement of two methane $(-\mathrm{CH}=)$ group by two pyridine type nitrogen $(-\mathrm{N}=)$ from furan. Depending on the position of nitrogen atom in the ring, oxadiazole exists in four possible isomers. 1, 3, 4-oxadiazole is widely exploited isomer in the area of drug discovery because of their broad range of biological activities. Literature survey revealed that the 1,3,4-oxadiazole derivatives is found to bear tremendous activities such as anti-diabetic, antimicrobial, anti-cancer, anticonvulsant, antioxidant, anti-Alzheimer's, anti-inflammatory, antiviral, cardiovascular, anti-tuberculosis, anti-pyretic, insecticidal, making it an important pharmacophore for follow up further drug research. This review emphasizes

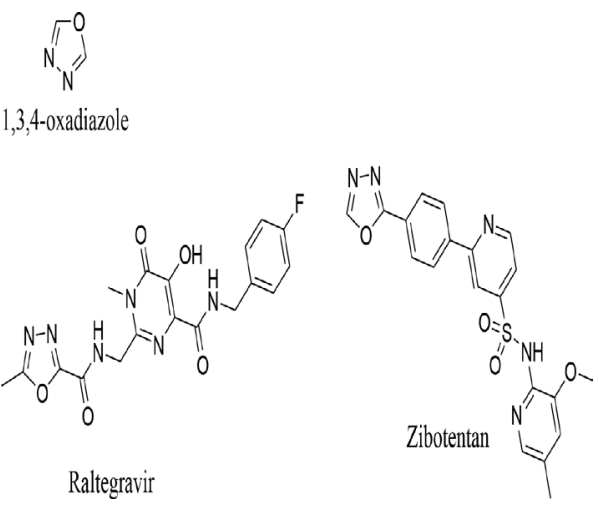

Submission Date: 04-04-2018; Revision Date: 30-10-2018; Accepted Date: 29-12-2018

DOI: 10.5530/ijper.53.2s.44 Correspondence: Ms. Rubina Bhutani,

Department of Pharmaceutical Chemistry, Delhi Institute of Pharmaceutical Sciences and Research, Pushp Vihar-3, M.B. Road, New Delhi, INDIA. Phone: +91 9958296439 E-mail: rubinabhutani23@ gmail.com

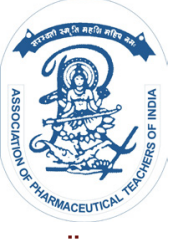

www.ijper.org 
on the compilation of latest update on biological profile of 1,3,4-oxadiazole derived compounds.

\section{PHARMACOLOGICAL ACTIVITY}

\section{Anti-Diabetic Activity}

Oxadiazole derivatives have been extensively studied for their anti-diabetic effect. A small series of novel benzothiazole clubbed oxadiazole mannich bases were synthesized and evaluated for their anti-hyperglycemic activity in STZ-induced model by R. Bhutani et al. ${ }^{4}$ All the compounds exhibited good to moderate activity and the compound 1 (Figure 1) showed highest anti-diabetic activity. A novel series of derivatives of 3-[2-(methylamino) methyl]5-\{[(2-phenylquinazolin-4-yl)oxy]methyl $\}$-1,3,4-oxadiazole-2 $(3 \mathrm{H})$-thione were prepared by Srinivas $\mathrm{S}$ et al. and were screened for GSK-3B inhibition activity. ${ }^{5}$ Three of the compounds 2, 3 and 4 of oxadiazolo-quinazoline series (Figure 2) exhibited good hypoglycemic activity.

A new series of fifteen 3-(5-cyclohexyl-1,3,4-oxadiazo2 -yl) N-substituted aniline analogs were prepared by $\mathrm{S}$. Kavitha et al. and were screened for in vitro alphaamylase inhibition activity. ${ }^{6}$ Among all the synthesized hits, compound 5 (Figure 3) and 6 (Figure 4) showed good $\alpha$ amylase inhibition activity than other compounds.

A.K. Iqbal et al. synthesized some novel thiazolidinone derivatives incorporating oxadiazole moiety and the compounds were evaluated for in vivo hypoglycemic activity in wistar rats. ${ }^{7}$ Compound 7 (Figure 5) showed comparable hypoglycemic activity to Pioglitazone.

Derivatives of oxadiazole containing 2-mercapto benzimidazole derivatives were synthesized and investigated for anti-diabetic activity using Oral Glucose Tolerance Test (OGTT) by R.V. Shingalapur et al. ${ }^{8}$ Compounds 8(a-d) (Figure 6) were found to have outstanding activity against standard.

S. Kun et al. synthesized a series of 2-( $\beta$-D-Glucopyranosyl)-5-(4,hydroxymethyl-1,2,3-triazol-1,-ylmethyl)1,3,4-oxadiazole derivatives. ${ }^{9}$ Analogs were assayed against rabbit muscle glycogen phosphorylase b. Compound 9 (2-phenyl-5-[1-( $\beta$-D-glucopyranosyl)-1,2,3-triazol-4-yl]1,3,4-oxadiazole (Figure 7) was found to had best inhibition.

\section{Antimicrobial activity}

Synthesis of novel benzothiazole based 1,3,4-oxadiazole derivatives containing benzothiazole were reported by Taher P. et al. ${ }^{10}$ Compounds 10(a-d) (Figure 8) synthesized were evaluated for antimicrobial active and they demonstrated good activity against Staphylococcus aureus, Escherichia coli.

Jignesh P.R. et al. have reported synthesis of novel oxoethylthio-1,3,4-oxadiazole derivatives synthesized

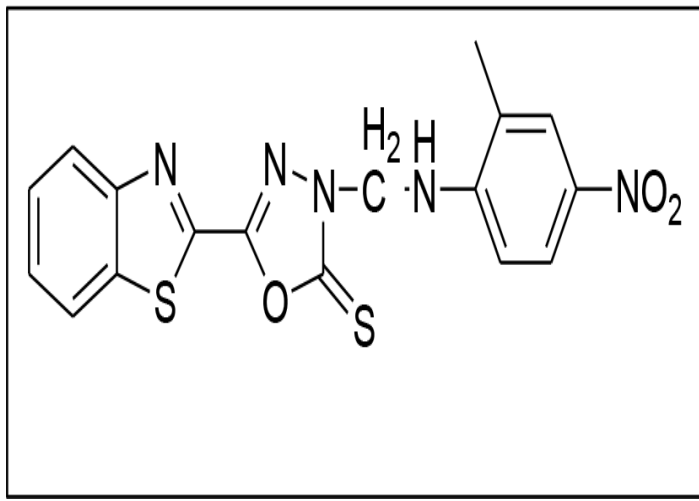

Figure 1: Chemical Structure of compound-1.

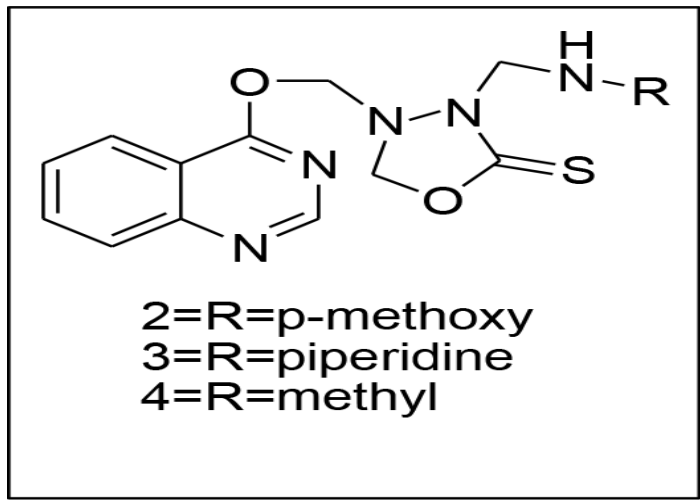

Figure 2: Chemical Structure of compounds2,3 and 4.

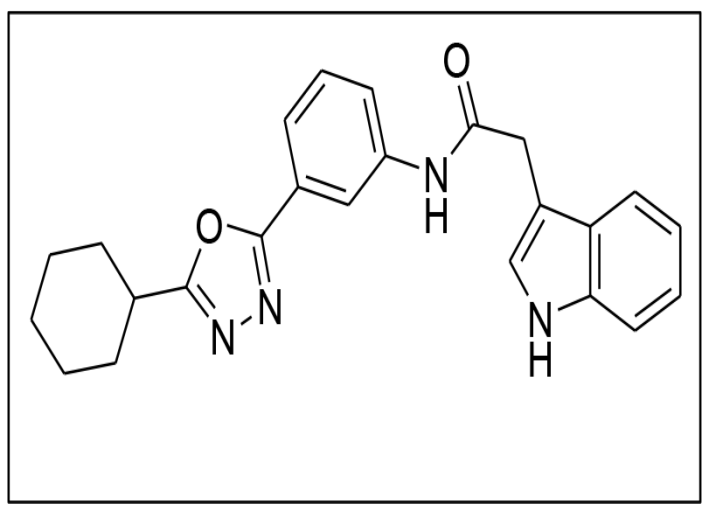

Figure 3: Chemical structure of compound 5.

using isonicotinohydrazide and were found active against Staphylococcus aureus, Escherichia coli, Bacillus cereus. ${ }^{11}$ Compounds (11a), (11d) having 2-chloro and 2-methylsubstitution respectively to the phenyl nucleus exhibited moderate to good activity against gram-negative bacteria and compounds (11b), (11c) having 3-chloro and 4-chloro substitution respectively to the phenyl nucleus exhibited moderate to good activity against gram positive bacteria only. (Figure 9) 


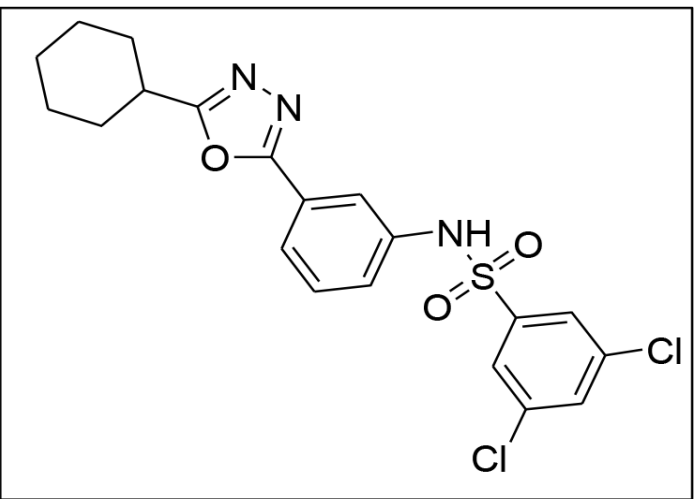

Figure 4: Chemical structure of compound 6.

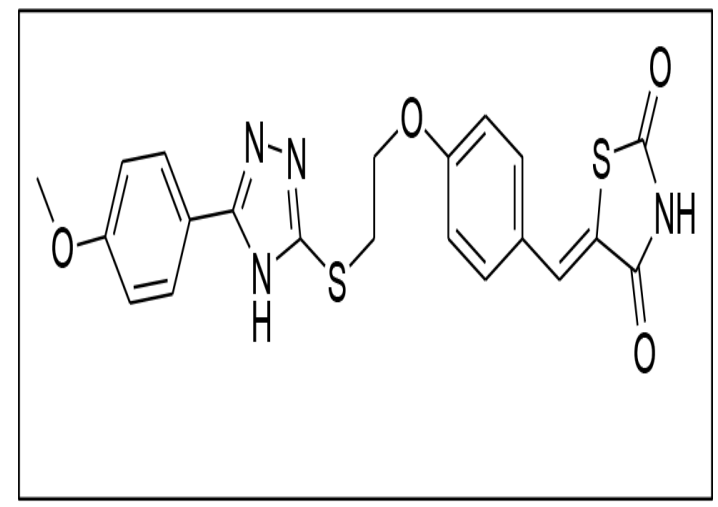

Figure 5: Chemical structure of compound 7

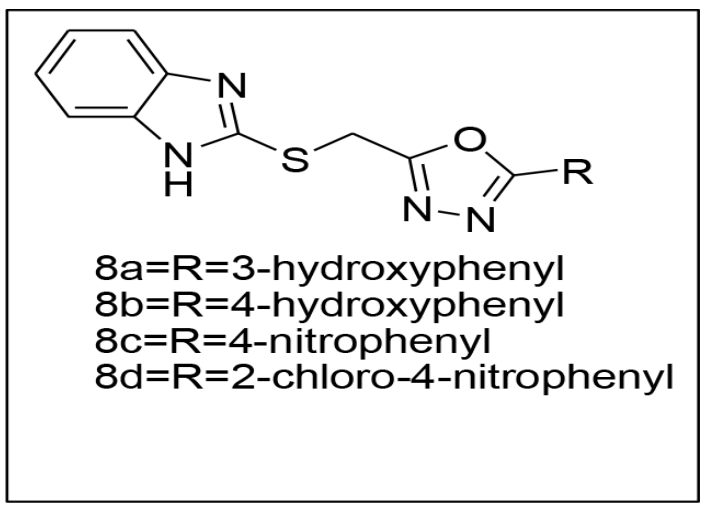

Figure 6: Chemical structure of compounds 8(a-d)

A novel series of substituted 1,3,4-oxadiazole derivatives 12(a-d) (Figure 10) were synthesized by Maryam Kouhkan et al. and investigated for their antimicrobial activity. ${ }^{12}$ All of the synthesized hits showed excellent antibacterial activity against Staphylococcus aureus and Staphylococcus epidermidis.

A small library of 1,4-benzodioxane based oxadiazole derivatives were synthesized by $\mathrm{H}$. Khalilullah et al. using an efficient synthetic route and were investigated for antibacterial activity. ${ }^{13}$ Compounds $13 \mathrm{a}, 13 \mathrm{~b}$ and $13 \mathrm{c}$

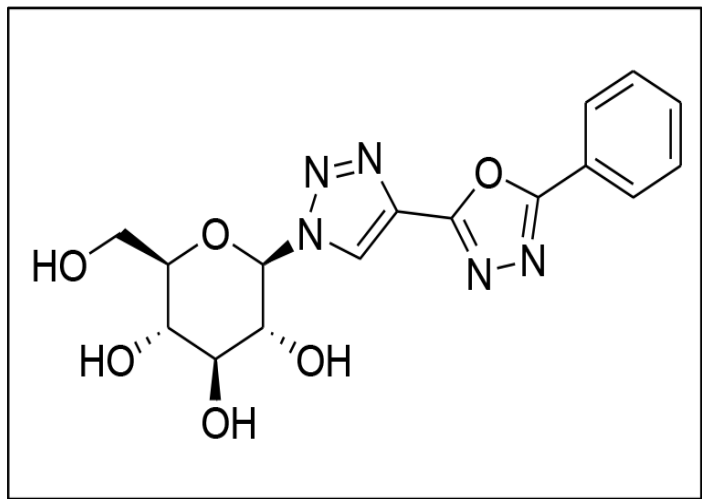

Figure 7: Chemical structure of compound 9.

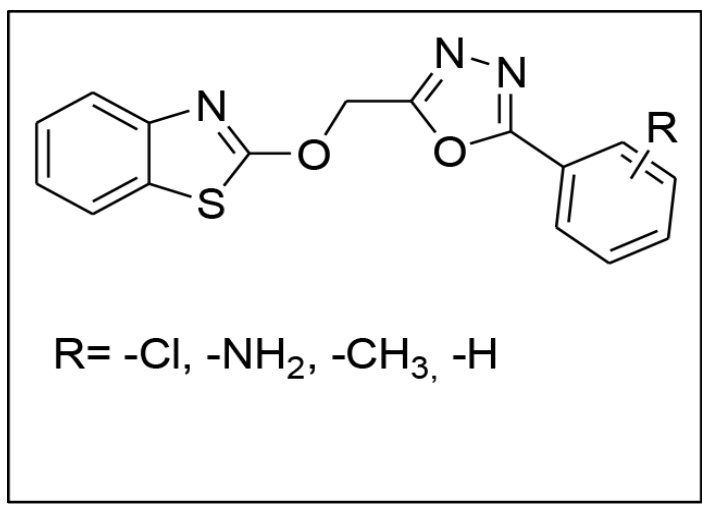

Figure 8: Chemical structure of compounds 10(a-d).

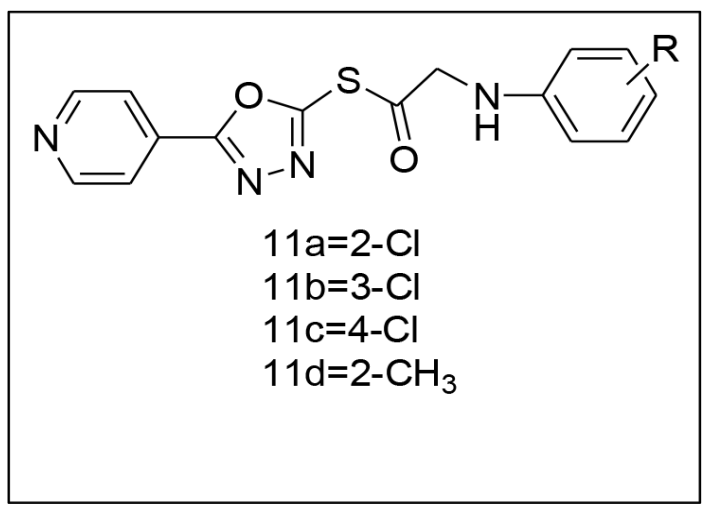

Figure 9: Chemical structure of compounds 11(a-d).

(Figure 11) showed magnificent activity against both gram positive and gram negative bacteria.

Salahuddin et al. developed a new series of oxadiazole bearing benzimidazole system as potent antibacterial and antifungal agents. ${ }^{14}$ It was indicated that that the compounds possessing electron withdrawing group and weakly activating group showed excellent activity against E. coli and S. aureus. The derivatives with $\mathrm{Cl}, \mathrm{NO}_{2}, \mathrm{Br}$ and methyl group in the oxadiazole system, compounds 14(a-d) were most potent against fungal strains. (Figure 12) 


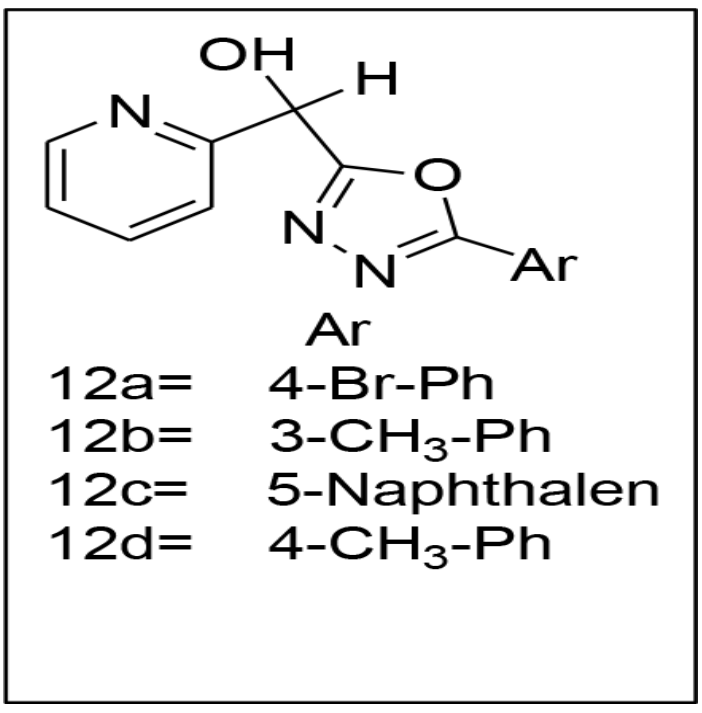

Figure 10: Chemical structure of compounds 12(a-d).

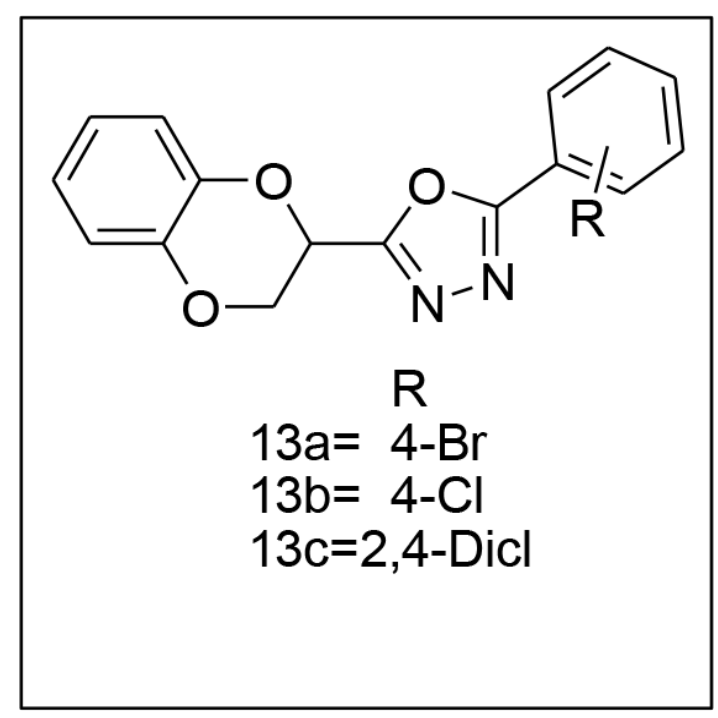

Figure 11: Chemical structure of compounds 13(a-c).

A series of ten new 1,3,4- oxadiazole derivatives bearing benzothiazole moiety were synthesized and screened for their antimicrobial potential by Gollapalli Naga Raju et al. ${ }^{15}$ Compounds 15a, 15b, 15d and 15e showed significant antibacterial activity while $15 \mathrm{c}$ and $15 \mathrm{e}$ (Figure 13) showed good antifungal activity.

\section{Anti-inflammatory activity}

G. Chawla et al. reported the syntheses and evaluation of 2-(3-bromo4-fluorophenyl)-5-substituted-1,3,4-oxadiazoles as anti-inflammatory agent. ${ }^{16}$ The pharmacological results revealed that, compound 16 (Figure 14) in which aryl ring was replaced by naphthyl ring, showed highest anti-inflammatory activity.

Durgashivaprasad et al. had explored the anti-inflammatory activity in acute and chronic models of two novel

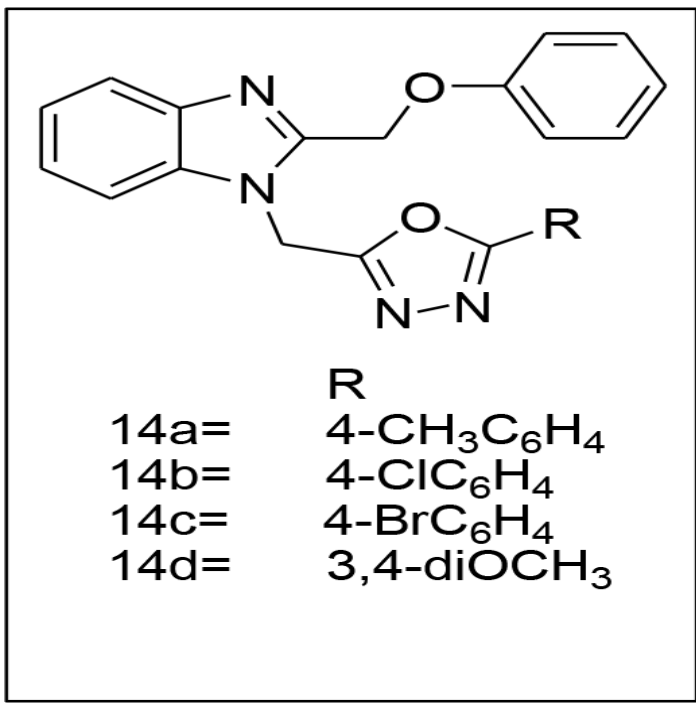

Figure 12: Chemical structure of compounds 14(a-d).

2,5-disubstituted-1,3,4-oxadiazoles. ${ }^{17}$ Compound OSD (compound 17) (Figure 15) was found to be better of the two compounds anti-inflammatory activity which may be due to the presence of o-phenol substitution at position 2 of oxadiazole ring.

Almasirad et al. designed and synthesized a new series of methyl-imidazolyl-1,3,4-oxadiazoles and were screened for anti-inflammatory activity. ${ }^{18}$ Analogs18 and 19 (Figure 16) showed good anti-inflammatory effect in wistar rats.

Kumar et al. evaluated the anti-inflammatory and analgesic potential of novel 2-(5-substituted-1,3,4-oxadiazole2-yl)-1,3-benzathiazole nine derivatives. ${ }^{19}$ Compounds 20(a-d) (Figure 17), displayed good anti-inflammatory activity than other compounds.

H.S. Abd-Ellah et al. synthesized a novel library of 1,3,4-oxadiazoles which is hybridized with oxime. ${ }^{20}$ The synthesized hits were screened for their anti-inflammatory, analgesic, antioxidant and ulcerogenic activities. Most of the tested compounds showed very good antiinflammatory activity with compound 21 (Figure 18) being more active than standard indomethacin. Docking studies of all the compounds were also performed.

M. Akhter et al. reported the synthesis and pharmacological screening of various aroylpropionic acid derivatives bearing 1,3,4-Oxadiazole nucleus. ${ }^{21}$ Compounds were evaluated for anti-inflammatory, analgesic, ulcerogenic activities and lipid peroxidation studies. 2-[3-(4 methylphenyl)-propane-3-one]5-(4-methoxyphenyl)-1,3,4-oxadiazoles (22a) and 2-[3-(2,4-dimethylphenyl)-propane-3-one]-5-(4methoxyphenyl)-1,3,4-oxadiazoles (22b) (Figure 19) 


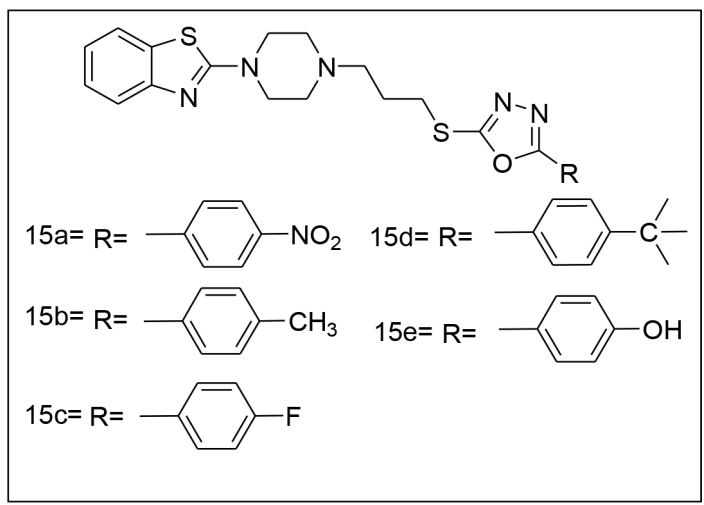

Figure 13: Chemical structure of compounds 15 (a-e).

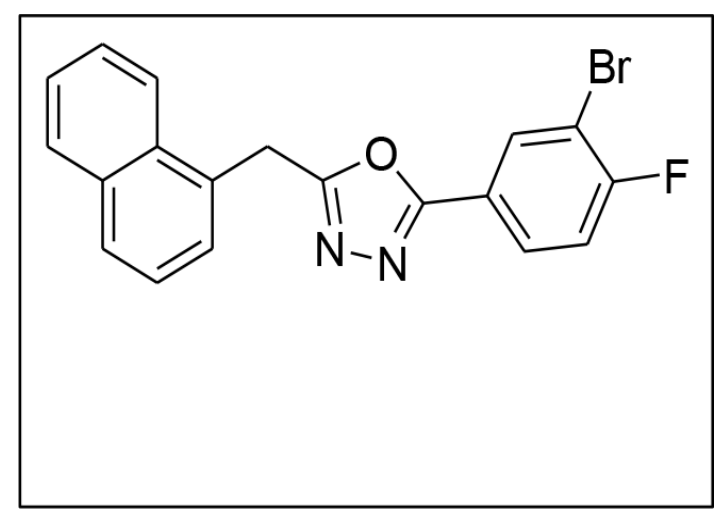

Figure 14: Chemical structure of compound 16.

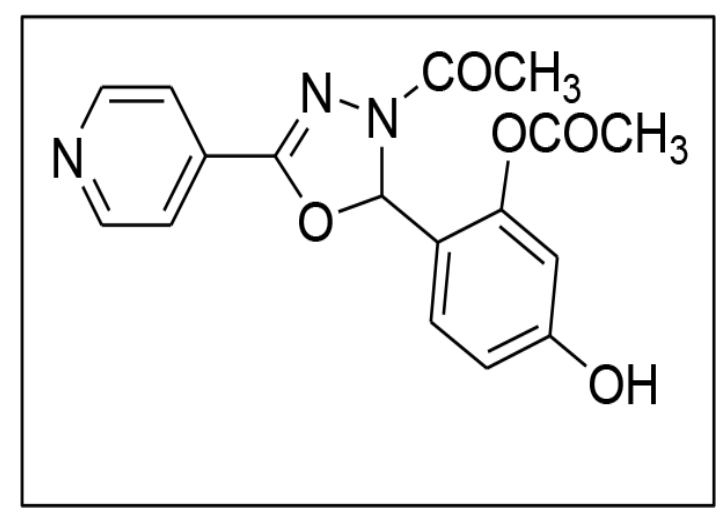

Figure 15: Chemical structure of compound 17.

were found equipotent to standard in inhibiting the rat paw edema.

\section{Anti-tubercular activity}

M. J. Ahsan et al. synthesized a new series of 1,5-dimethyl-2-phenyl-4-\{[(5-aryl-1,3,4-oxadiazol-2-yl) methyl]amino $-1,2$-dihydro-3H-pyrazol-3-one and all the derivatives were screened for anti-tubercular activity. ${ }^{22}$ Among the synthesized derivatives, compound 23 (Figure 20) showed marked activity against Mycobac-

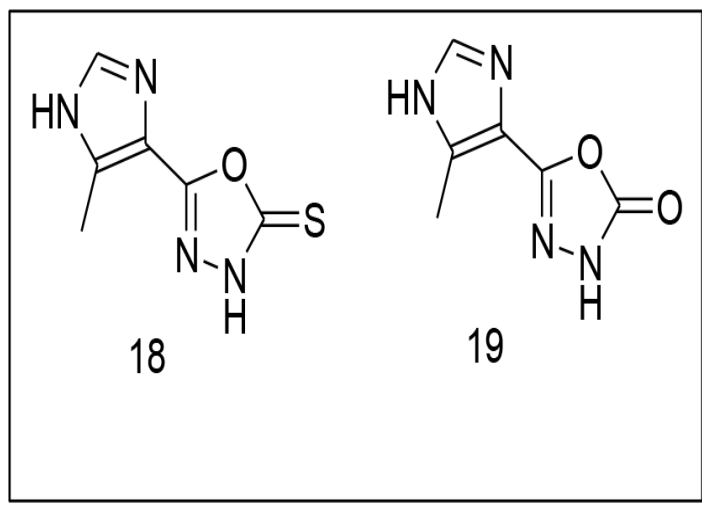

Figure 16: Chemical structure of compounds 18, 19.

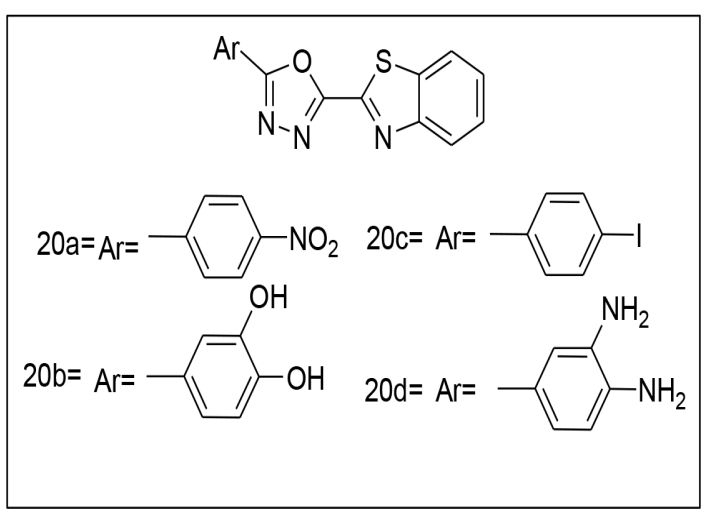

Figure 17: Chemical structure of compounds 20(a-d).

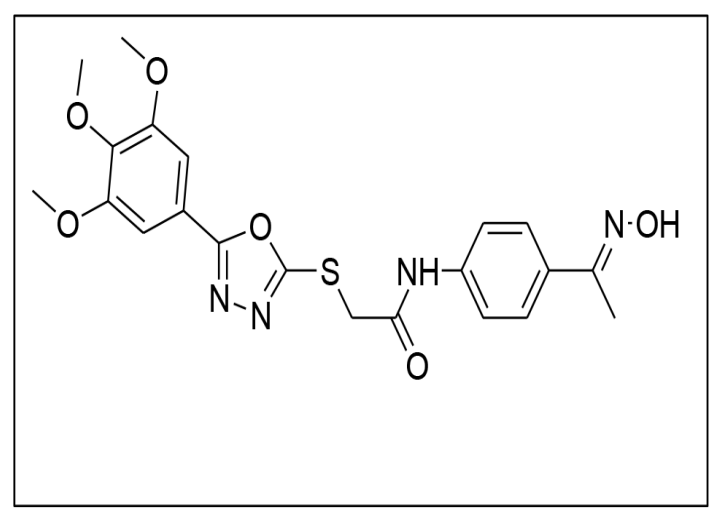

Figure 18: Chemical structure of compound 21.

terium tuberculosis $\mathrm{H} 37 \mathrm{Rv}$ and isoniazid resistant $\mathrm{M}$. tuberculosis.

Chandrasekera et al. tested the potential of newly synthesized 3-substituted benzothiophene-1,1-dioxide derivatives as inhibitors of virulent Mycobacterium tuberculosis. ${ }^{23}$ The results revealed that the substitution at the C-3 position of the benzothiophene-1,1 dioxide series influenced the anti-tubercular activity. Oxadiazoles 24(a-d) (Figure 21) showed good anti-tubercular 


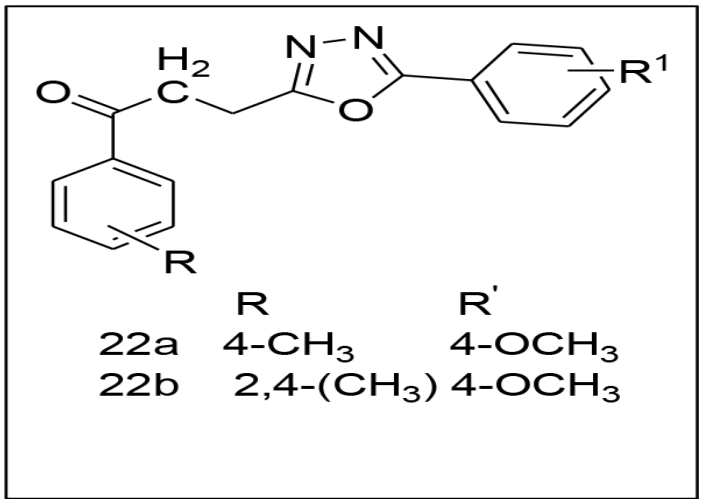

Figure 19: Chemical structure of compounds 22(a-b).

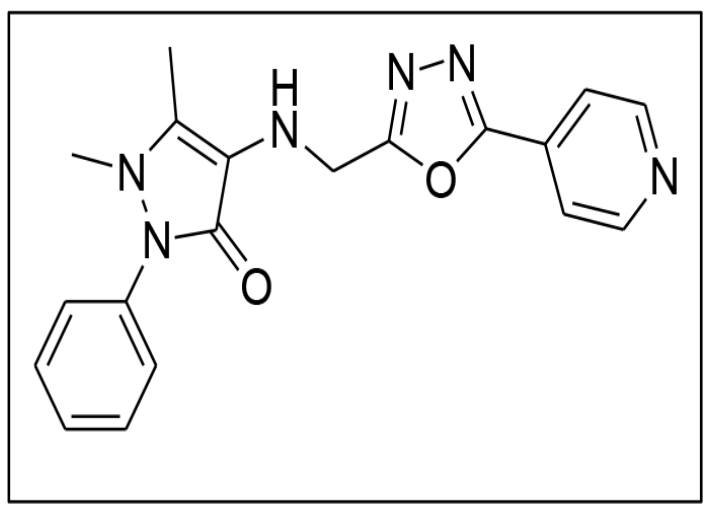

Figure 20: Chemical structure of compound 23.

activity while thiazoles, imidazoles and thiadiazoles had little activity.

Galina Karabanovich et al. investigated the novel synthesized 5-substituted-2-[(3,5-dinitrobenzyl)sulfanyl]-1,3,4oxadiazoles and 1,3,4-thiadiazoles as a new class of anti-tubercular agents. ${ }^{24}$ Most of the compounds 25(a-p) Figure 22 showed excellent in vitro activity against Mycobacterium tuberculosis.

G.V. Suresh Kumar et al. performed the preliminary antitubercular screening for 2-substituted5-[isopropylthiazole] clubbed 1,2,4-triazole and 1,3,4- oxadiazole derivatives against Mycobacterium tuberculosis $\mathrm{H} 37 \mathrm{Rv}^{25}$ Results of anti-tubercular activity against M. tuberculosis revealed that compound26 (Figure 23) showed two fold enhanced potency than parent compound.

Ladania GG et al. synthesized new series of hits by coupling 1,3,4-oxadiazole with substituted quinoline moiety using molecular hybridization using different catalyst and solvents. ${ }^{26}$ Primary screening of obtained compounds were performed against Mycobacterium tuberculosis H37Rv strain using Lowenstein-Jensen medium. The result showed that compounds 27(a-d) (Figure 24) were found to possess excellent activity.

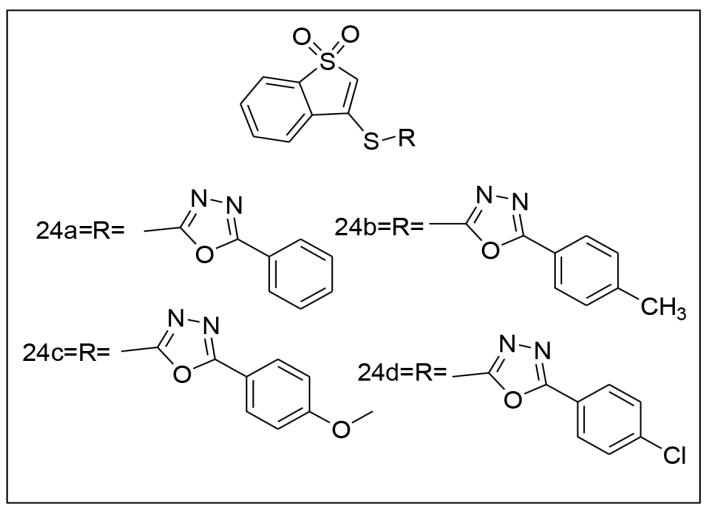

Figure 21: Chemical structure of compounds 24(a-d).

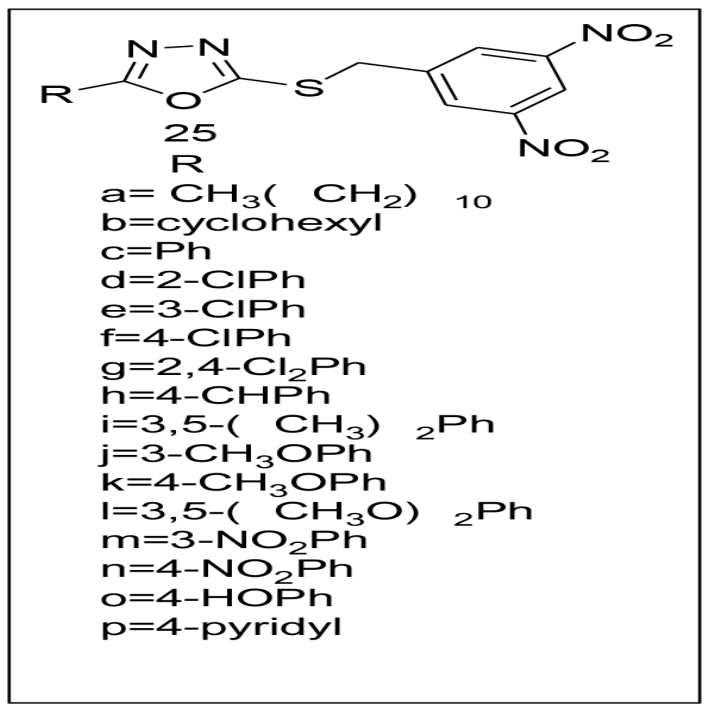

Figure 22: Chemical structure of compounds 25(a-p).

\section{Anti-alzheimer Activity}

Attaby et al. synthesized a number of new heterocyclic compounds, some having 1,3,4- oxadiazole derivatives and all were tested for anti-alzheimer activity. ${ }^{27}$ Many compounds showed good activity and compound 28 (Figure 25) having oxadiazole moiety found to have high potency as anti-alzheimer agents relative to Flurbiprofen. New chemical entities having 1,3,4-oxadiazole moiety of were synthesized and tested for their in vitro acetylcholinesterase (AChE) inhibitory potency by Kamal et al..$^{28}$ All compounds derived exhibited good inhibitory activity against AChE enzyme. Derivative 29 (Figure 26) showed $\mathrm{IC}_{50}$ value of $37.65 \mathrm{IM}$ and resulted as a promising anti-alzheimer agent

Saitoh et al. designed, synthesized and reported SAR of a new library of oxadiazole derivatives as GSK-3 $\beta$ inhibitors which is promising agent for treating alzheimer's disease. ${ }^{29}$ Among all derivatives compound 30 (Figure 27) 


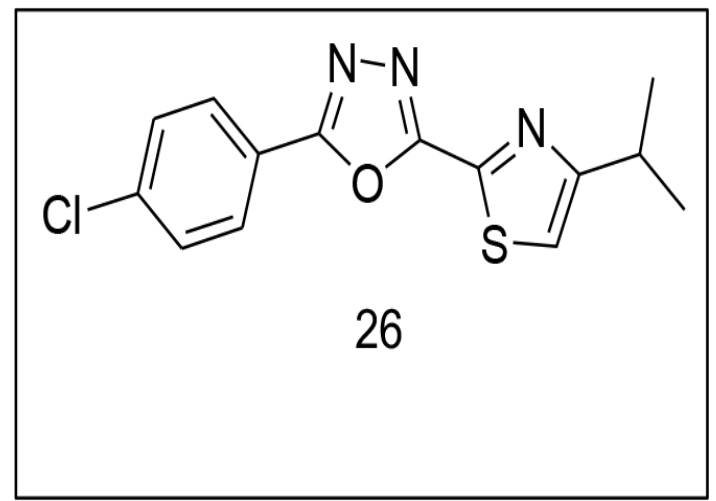

Figure 23: Chemical structure of compound 26.

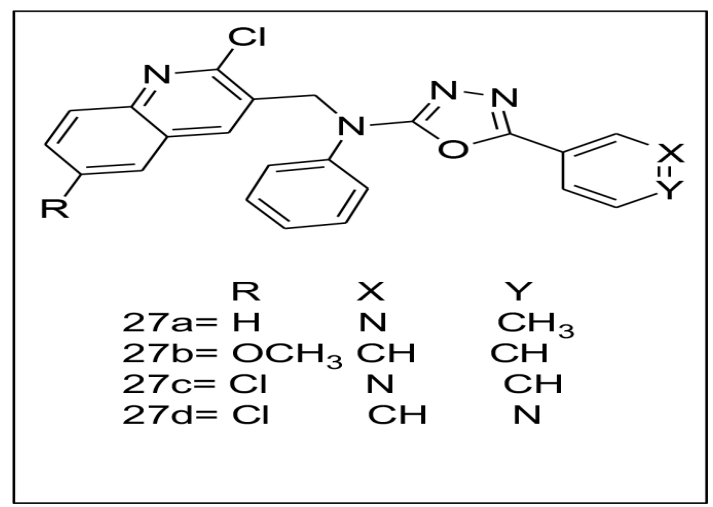

Figure 24: Chemical structure of compounds 27(a-d).

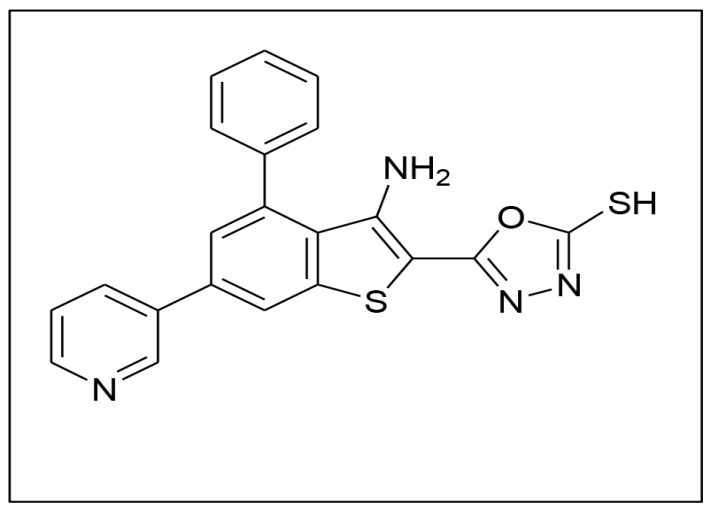

Figure 25: Chemical structure of compound 28.

was found to show high selectivity and potency for GSK-3 $\beta$ inhibition in vitro.

\section{Antioxidant Activity}

Shridhar et al. synthesized novel 3,5-Bis(alkyl-1,3,4-oxadiazole-2-yl azo dyes 4(a-f) and tested for in vitro antioxidant properties. ${ }^{30}$ Results showed that all compounds have significant antimicrobial and antioxidant activities. DPPH assay was done on $4 \mathrm{a}-\mathrm{f}$ at different concentrations and 31a and 31b (Figure 28) showed significant DPPH scavenging activity $(>70 \%)$ due to best substitutions.

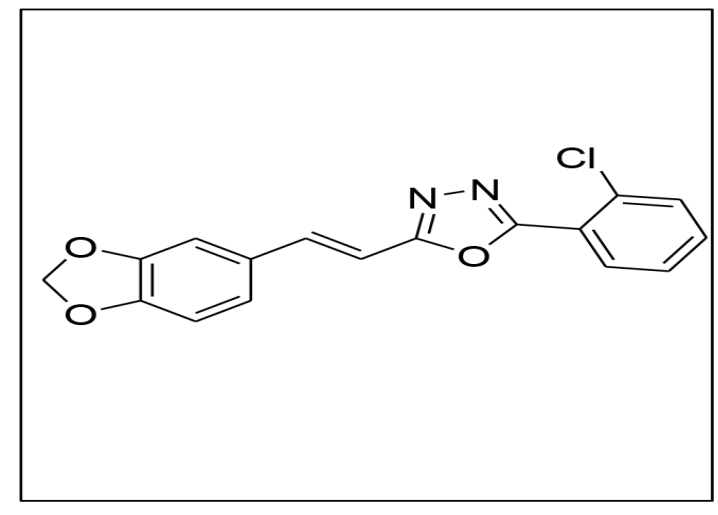

Figure 26: Chemical structure of compound 29.

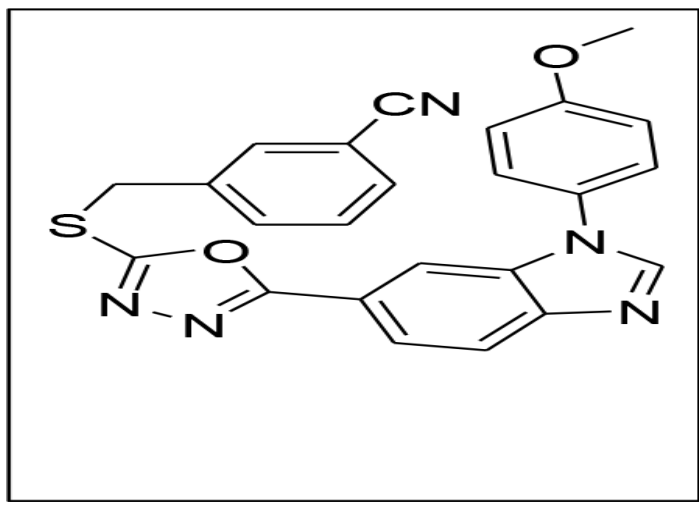

Figure 27: Chemical structure of compound 30.

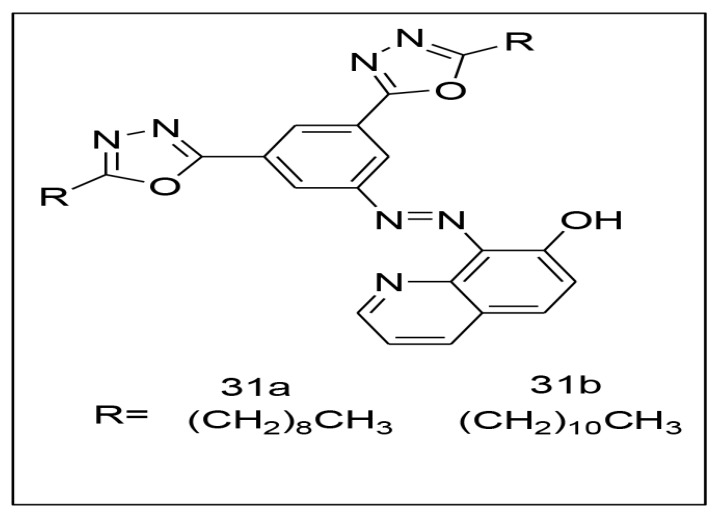

Figure 28: Chemical structure of compounds 31(a-b).

Abdelmonem et al. synthesized some novel oxadiazole derivatives and tested for antioxidant activity. ${ }^{31}$ All derivatives, compound 32 (Figure 29) were found to be potent antioxidant agents.

Patrao et al. synthesized a new entities of 1-(substituted)2-(\{5-[(naphthalen-1/2 yloxy) methyl]-1,3,4-oxadiazol2 -yl $\}$ sulfanyl)ethanone. They were tested for antioxidant activities and showed promising results. ${ }^{32}$ Compound 33 (Figure 30) exhibited good antioxidant activity.

A library of new 5-(2-amino-5-methylthiazol-4-yl)-1,3,4oxadiazole-2-thiol derivatives was prepared and evaluated 
for antioxidant potential by Kikkeri et al. ${ }^{33}$ Compounds $34 \mathrm{a}, 34 \mathrm{~b}$ and $34 \mathrm{c}$ (Figure 31) gives best scavenging effect against the free radicals.

Novel series of 2,5-disubstituted-1,3,4-oxadiazole derivatives synthesized and screening for their antimicrobial and antioxidant activities were done by Sindhe et al. ${ }^{34}$ The results showed that 35(a-c)(Figure 32) displayed best antioxidant activity.

Mihailovic et al. synthesized some 1,3,4-oxadiazole derivatives having phenolic acid moieties and examined for their scavenging potential ie.anti-oxidant activity by scavenging stable DPPH (2,2-diphenyl-1-picrylhydrazyl) radicals. ${ }^{35}$ Compounds 36(a-d) (Figure 33) exhibited best DPPH scavenging activity.

Bharatiya et al. synthesized a novel set of 2-N-phenyl piperazino methylene-4- (4'-amino, 2'-nitro phenyl)5-mercapto-1,3,4-oxadiazole analogs which were tested for their antioxidant potential. ${ }^{36}$ Compounds $37 \mathrm{a}$ and 37b (Figure 34) showed good antioxidant activity.

\section{Anticonvulsant activity}

Vaishali and Bahar Ahmed synthesized 2-(substitutedphenyl)-2-methyl-5styryl-2,3-dihydro-[1,3,4]oxadiazole derivatives as anticonvulsant agents. ${ }^{37}$ Among the synthesized hits 38 and 39 (Figure 35) possess good significant activity. Docking study was also done of all the prepared compounds on PDB ID: 4COF.

A new series of 2-(substituted phenyl)amino-5-(4-pyridyl)4H-1,3,4-oxadiazole derivatives was synthesized from isoniazid and various substituted isothiocyanates by $\mathrm{M}$ Shaharyar et al. ${ }^{38}$ Synthesized compounds were screened for their anticonvulsant activity. Compound 2-(4-chlorophenyl) amino-5-(4-pyridyl)1,3,4-oxadiazole (40) (Figure 36) found to have extremely good anticonvulsant activity.

Harish Rajak et al. designed and synthesized a series of new substituted semicarbazones containing 1,3,4oxadiazole nucleus, 41(a-n) (Figure 37) and tested for their anticonvulsant potential through MES and scPTZ models. ${ }^{39}$ Results demonstrated that hits bearing the groups like hydroxy or nitro on phenyl possess high potency in MES and scPTZ models.

Tabatabai A et al. synthesized some phenoxyphenyl1,3,4-oxadiazole derivatives and evaluated them for anticonvulsant activity using pentylene tetrazole induced lethal convulsion test. ${ }^{40} \mathrm{It}$ was indicated that compound 42 (Figure 38) with an amino substituent on 5 position of 1,3,4-oxadiazole ring has a good effect whereas

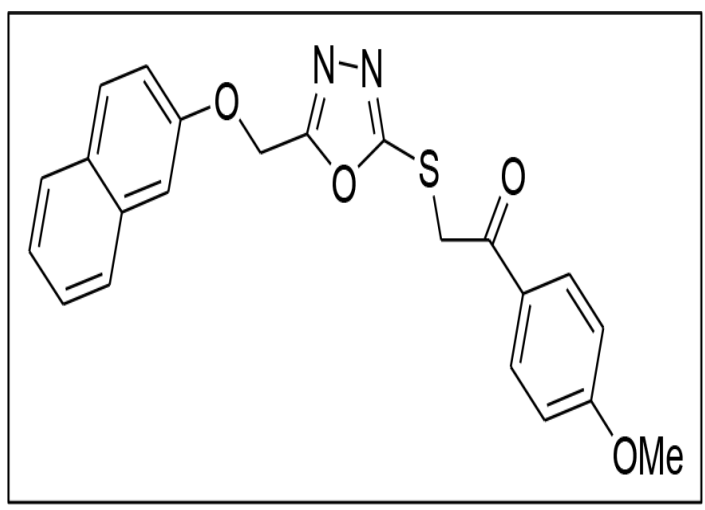

Figure 30: Chemical structure of compound 33.

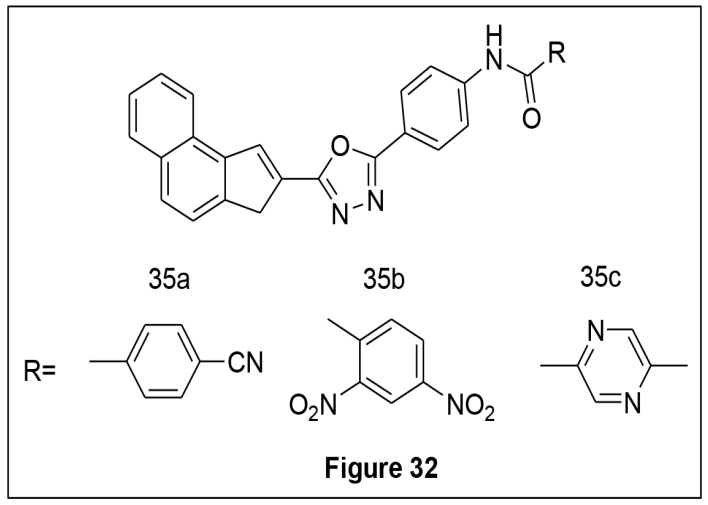

Figure 32: Chemical structure of compounds 35(a-c). 


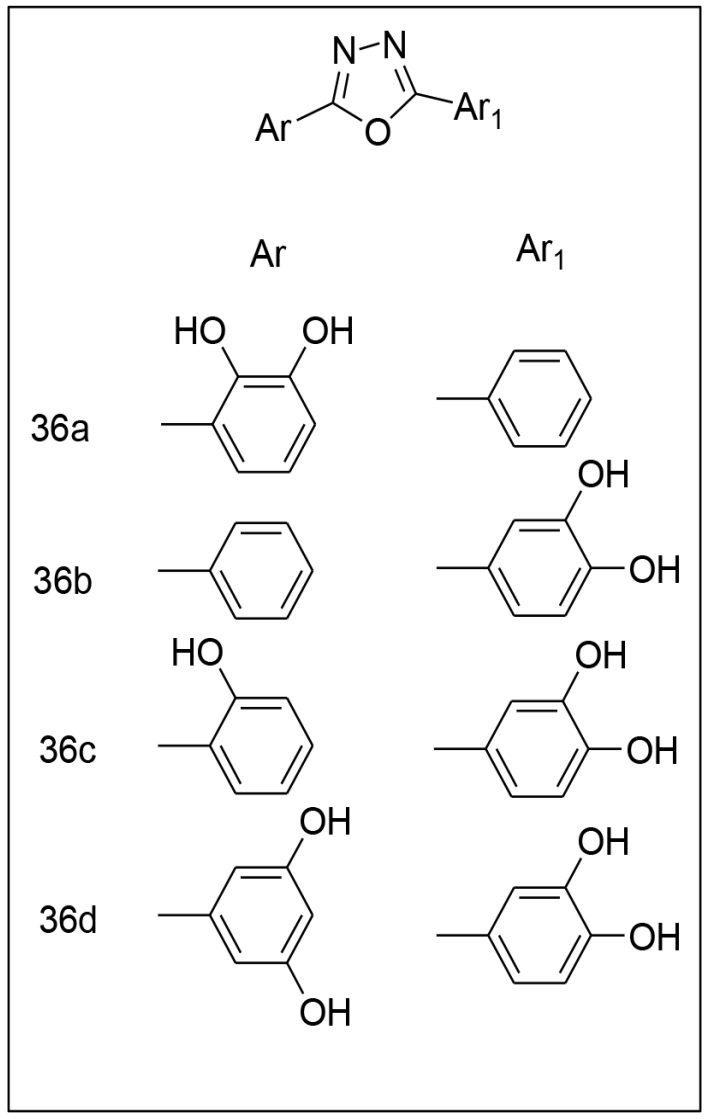

Figure 33: Chemical structure of compounds 36 (a-d).

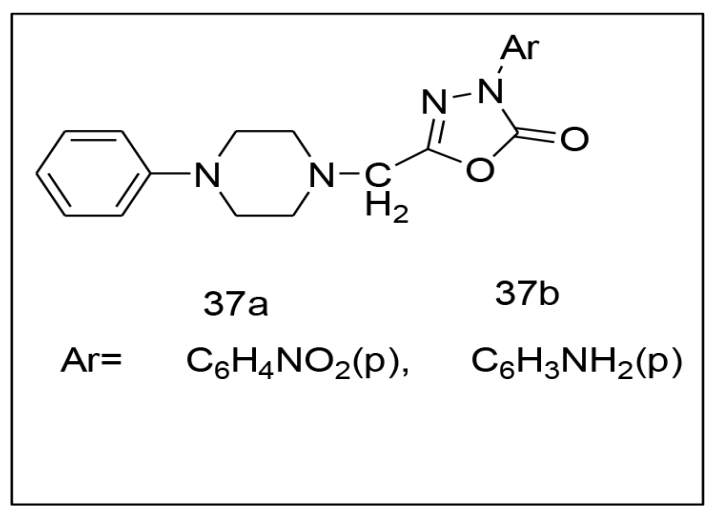

Figure 34: Chemical structure of compounds 37 (a-b).

replacement of amino group with $\mathrm{H}, \mathrm{OH}, \mathrm{SH}$ or $\mathrm{SCH}_{3}$ diminish the anticonvulsant effect.

A library of novel phthalimide derivatives of 1,3,4-oxadiazole were synthesized and screened for their anticonvulsant activity by Mashooq A. Bhat et al. ${ }^{41}$ Results showed that a number of synthesized title compounds demonstrated good activity with compound 43 (Figure 39) showing excellent anti convulsant activity comparable to standard i.e. phenytoin.

S J Gilani et al. synthesized a novel series of Isoninicotinic acid hydrazide incorporated derivatives of

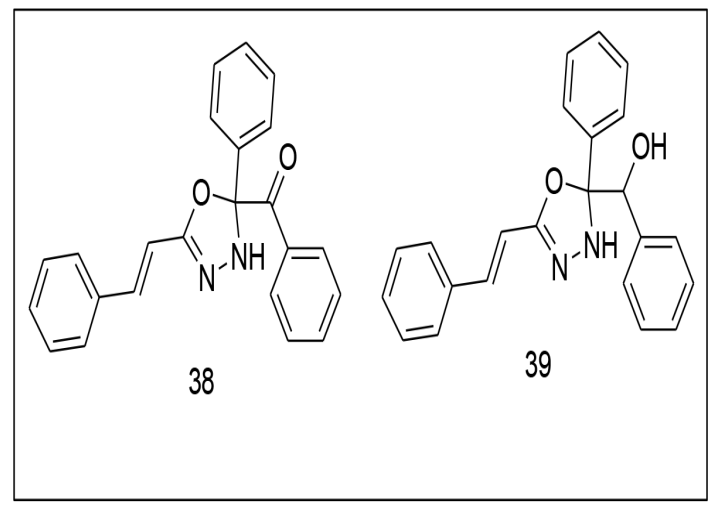

Figure 35: Chemical structure of compounds 38, 39.

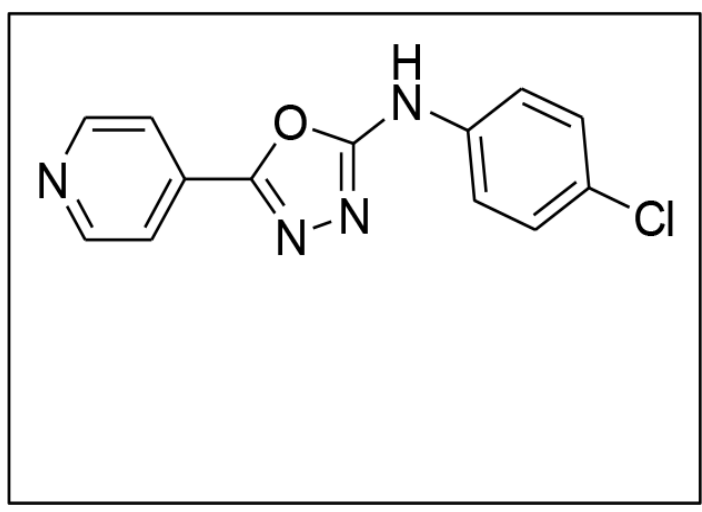

Figure 36: Chemical structure of compound 40.

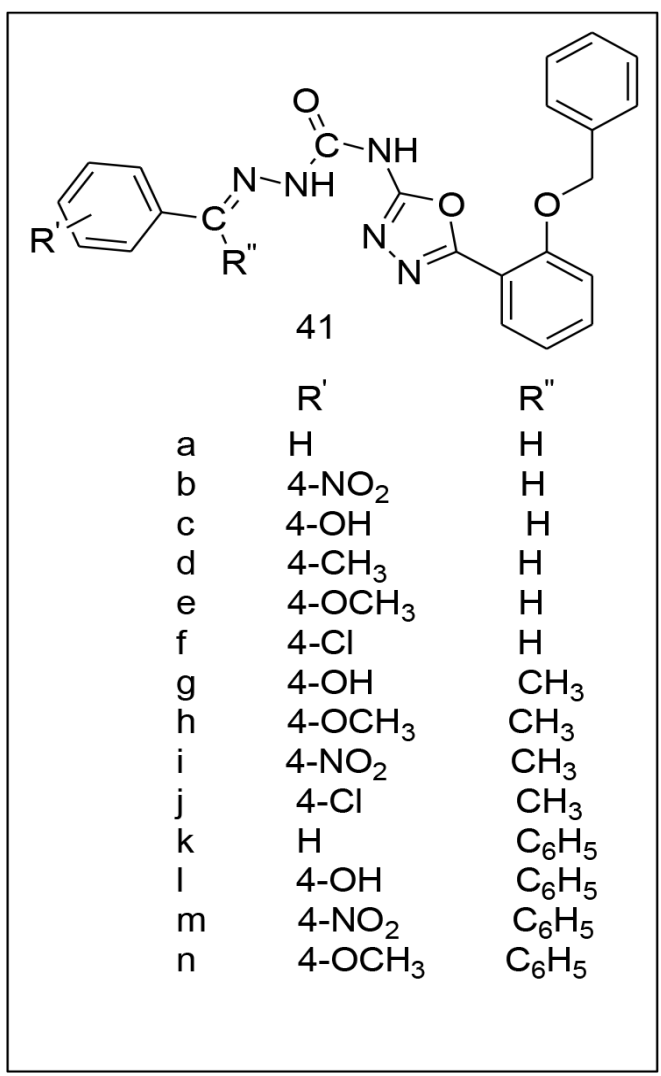

Figure 37: Chemical structure of compounds 41 (a-n). 


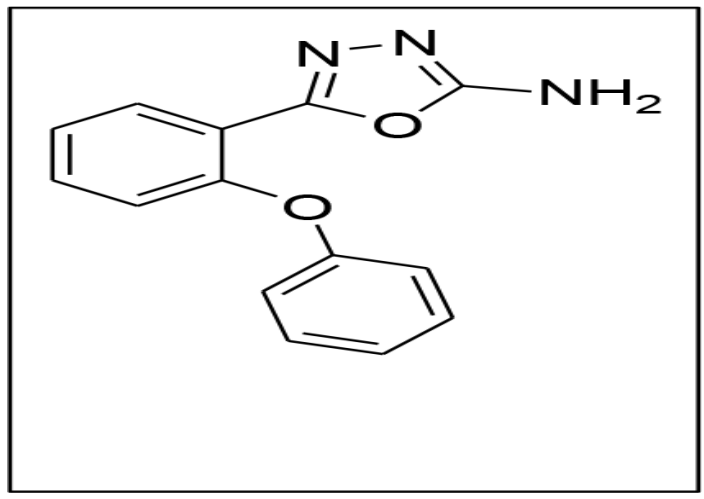

Figure 38: Chemical structure of compound 42.

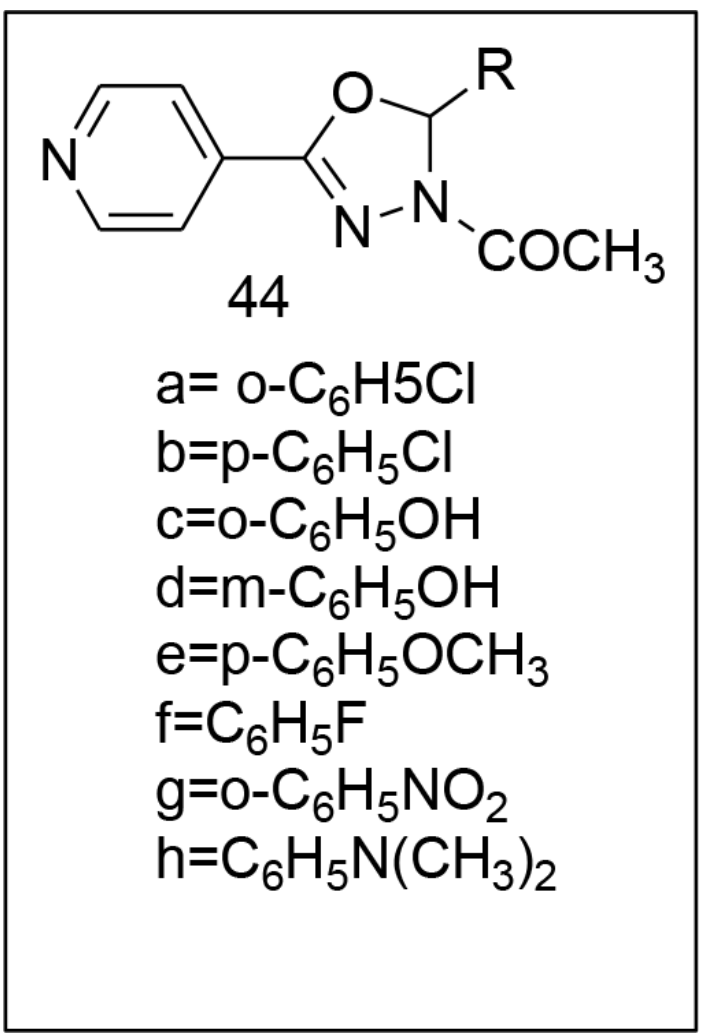

Figure 40: Chemical structure of compounds 44(a-h).

1,3,4-oxadiazole and were screened for anticonvulsant activity against maximal electroshock induced seizures (MES) and subcutaneous pentylenetetrazole (scPTZ) induced models. ${ }^{42}$ All the synthesized compounds 44 (a-h) (Figure 40) were found to be active in MES and most of compounds were found active in scPTZ model.

\section{Antiviral}

W. A. El-Sayed et al. prepared a series of new 5-[(naphthalen-1-yloxy)methyl]-1,3,4-oxadiazole derivatives and were screened for their anti-HIV activity. ${ }^{43}$ Results indicated that compound 45 (Figure 41) showed the excellent antiviral activity. Results revealed that the

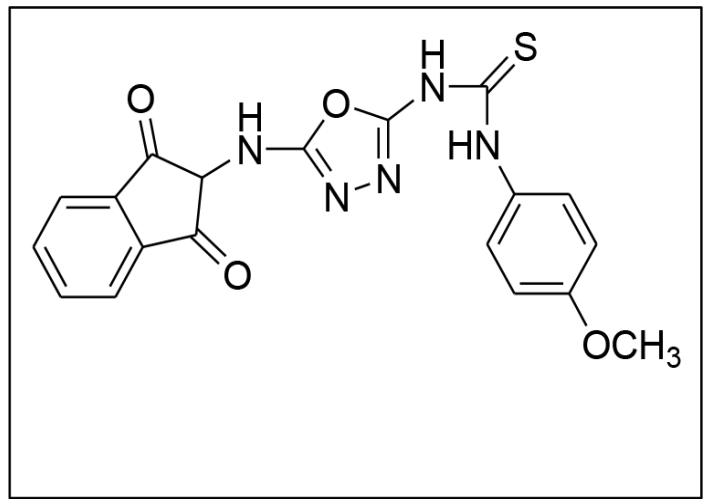

Figure 39: Chemical structure of compound 43.

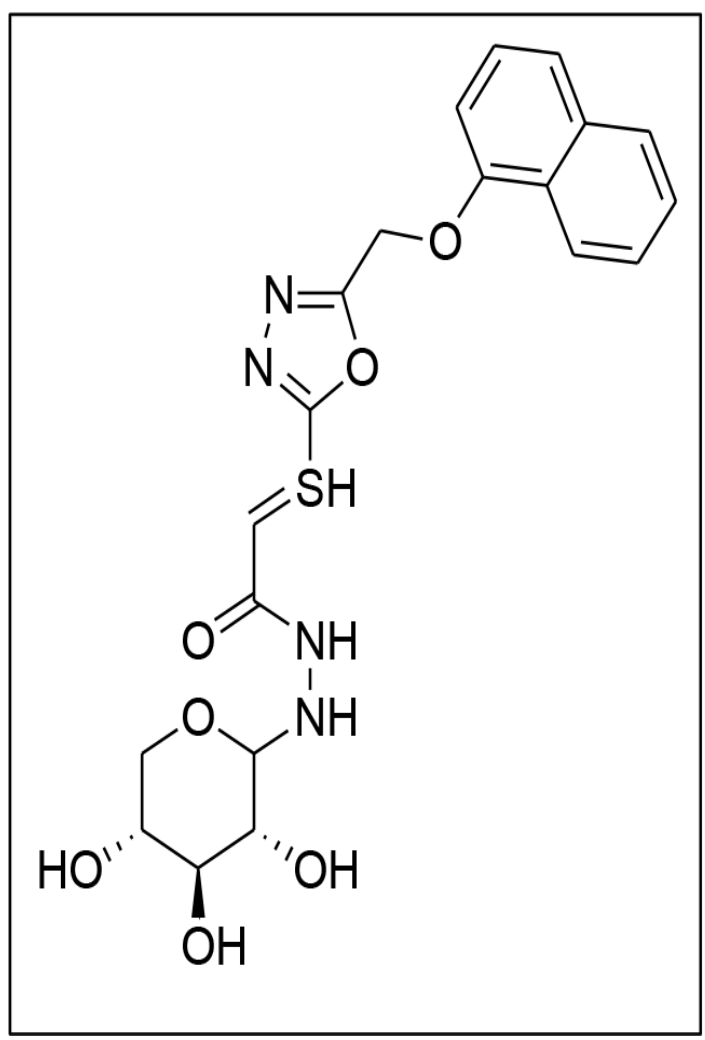

Figure 41: Chemical structure of compound 45.

substitution of a free hydroxyl sugar moiety increases the antiviral activity compared to O-acetylated substituted derivatives.

A new library of novel 1,3,4-oxadiazole thioether derivatives bearing 2-methylpyrimidin-4-amine group were synthesized by W. Wu et al. and evaluated for their antiviral activity against $\mathrm{TMV}{ }^{44}$ Antiviral results demonstrated that compound 46 (Figure 42)showed the best effect against TMV, even better than standard.

Liangrun Dong et al. performed the synthesis of novel thioether derivatives containing 1,3,4-oxadiazole/thiadiazole and emodin moieties. ${ }^{45}$ The derivatives were evaluated for antiviral activity against TMV using the 


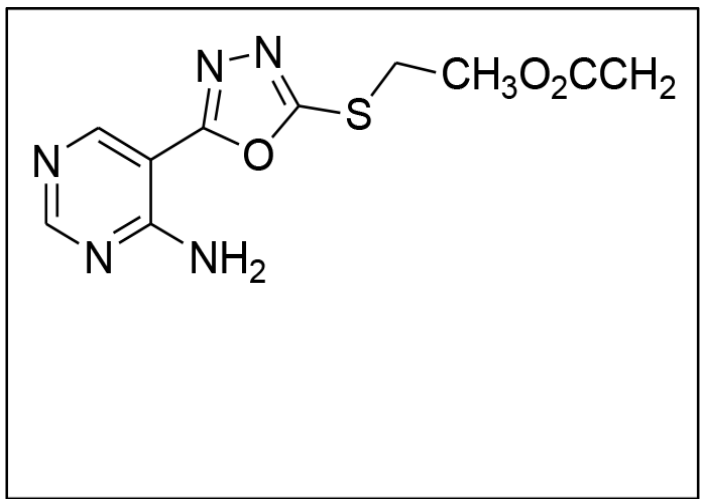

Figure 42: Chemical structure of compound 46.

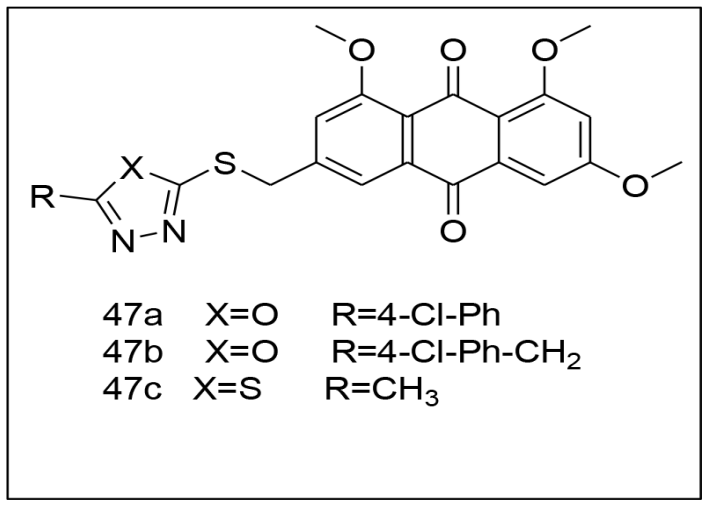

Figure 43: Chemical structure of compounds 47(a-c).

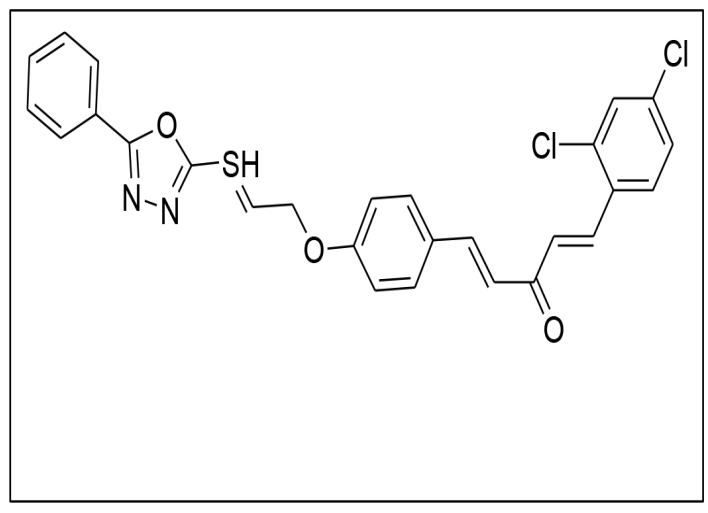

Figure 44: Chemical structure of compound 48.

half-leaf method. The results demonstrated that among the prepared compounds, 47a, 47b and 47c (Figure 43)possessed significant antiviral activity with inhibition rates of $50.51 \%, 52.08 \%$ and $54.62 \%$, respectively, which were comparable to that of reference $(53.40 \%)$.

Xiuhai Gan et al. designed and synthesized a novel series of 1,4-pentadien-3-one derivatives containing the 1,3,4-oxadiazole moiety and screened for their anti-viral activity. ${ }^{46}$ It was indicated that some of the synthesized compounds showed moderate to good antiviral activities at $500 \mathrm{mg} \mathrm{L}^{-1}$. Compound 48 (Figure 44) was found

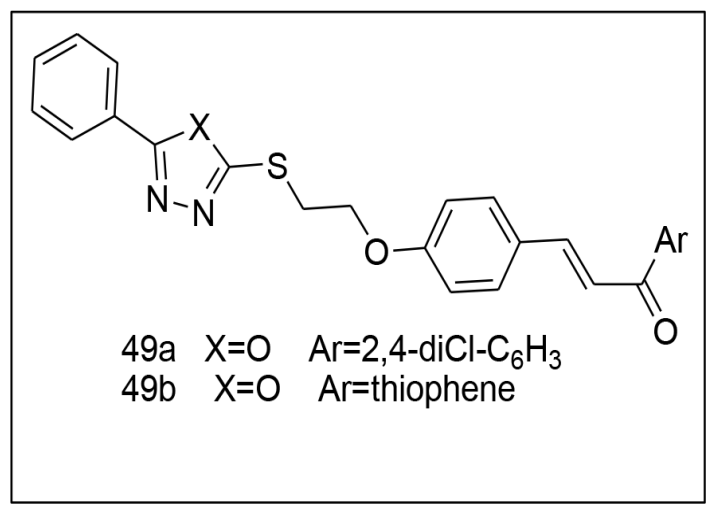

Figure 45: Chemical structure of compounds 49(a-b).

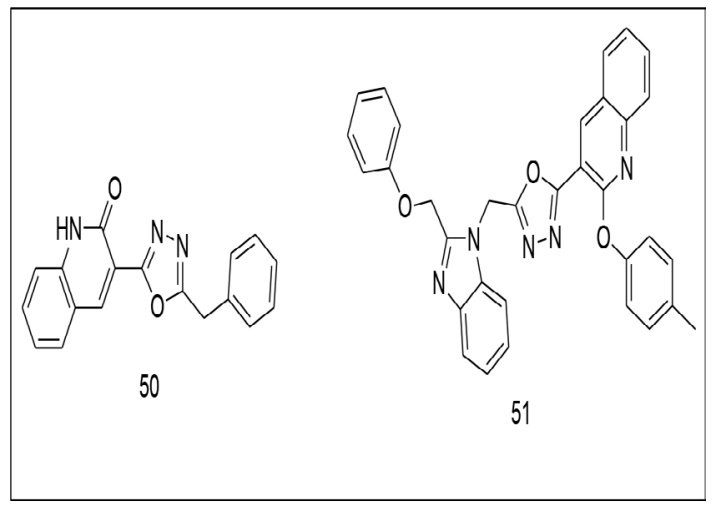

Figure 46: Chemical structure of compounds 50, 51.

to demonstrate the excellent protective activity, with $\mathrm{EC}_{50}$ value of $135.56 \mathrm{mg} \mathrm{L}^{-1}$, which were better to ribavirin.

A small library of twenty six new 1,3,4-oxadiazole/ thiadiazole-chalcone analogs were prepared and tested for antiviral activity. ${ }^{47}$ Compounds $49(\mathrm{a}-\mathrm{b})$ (Figure 45) showed outstanding anti-viral activity with the $\mathrm{EC}_{50}$ values of $33.66,33.97,33.87$ and $30.57 \mathrm{mg} / \mathrm{mL}$, respectively, with reference to standard. SAR study was also done which indicated that smaller aromatic ring and electron-with drawing groups will increase the antiTMV effect.

\section{Anti-cancer}

Salahuddin et al. synthesised new 2,5-disubstituted 1,3,4-oxadiazole analogs and were evaluated for anticancer activity. ${ }^{48}$ Compound 50(NSC-776965) and compound 51 (NSC 776971) (Figure 46) showed the best results against cancer among the synthesized hits.

Mohamed Jawed Ahsan et al. reported the synthesis of some oxadiazole as antiproliferative agents. ${ }^{49} \mathrm{Com}-$ pound 52 (Figure 47) expressed highest antiproliferative activity towards HOP-92 human cancer cell lines at $10 \mu \mathrm{M}$ concentration. 


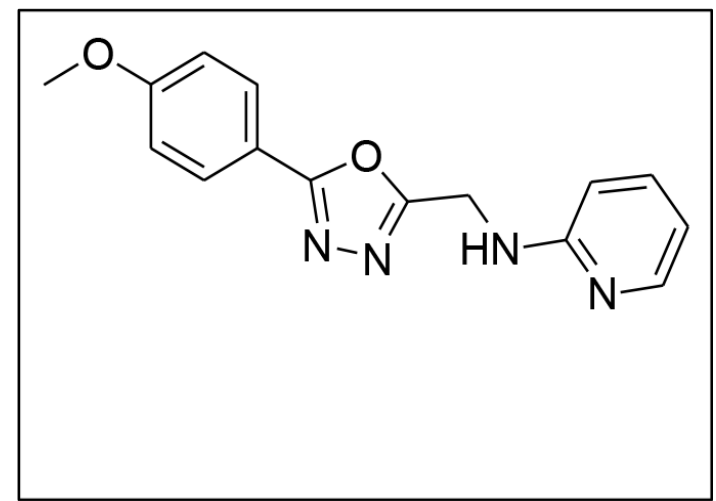

Figure 47: Chemical structure of compound 52.

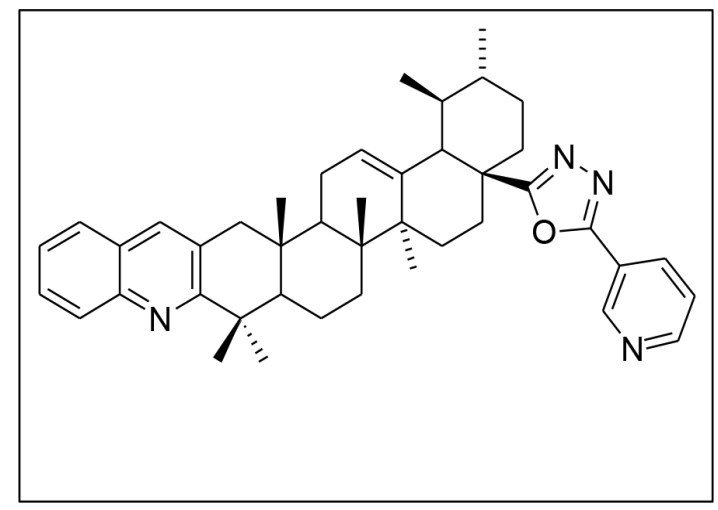

Figure 48: Chemical structure of compound 53.

$\mathrm{Gu}$ W et al. designed and synthesized new series quinoline derivatives of ursolic acid and were tested for in vitro anti-cancer activity against MDA-MB-231, HeLa and SMMC-7721 cell lines. ${ }^{50}$

Compound53 (Figure 48) showed remarkable anticancer activity against MDA-MB-231, HeLa and SMMC7721 cells comparable to etoposide.

F.A.F. Ragab et al. designed and synthesized a new series of DHPMs containing 1,3,4-oxadiazole moiety as monastrol analogues. ${ }^{51}$ The prepared derivatives were evaluated for their cytotoxic activity against 60 cancer cell lines at one dose $(10 \mu \mathrm{M})$. Compounds 54 against HL-60 (TB) and 55 (Figure 49) against MOLT-4, were found to be more active than monastrol.

Ahmet Özdemir et al. synthesized some novel oxadiazole, thiadiazole and triazole analogs and were tested for their inhibitory effects on MMPs. ${ }^{52}$ Compounds 56 (a-b) (Figure 50) showed most promising anticancer effects on A549 and C6 cell lines similar to standard cisplatin. These analogs were also the most active MMP-9 inhibitors. Docking study has also been performed.

A. Husain et al. designed and synthesized two novel series of benzimidazole bearing oxadiazole and triazolothiadiazoles as a potential anticancer agents. ${ }^{53}$ Anticancer

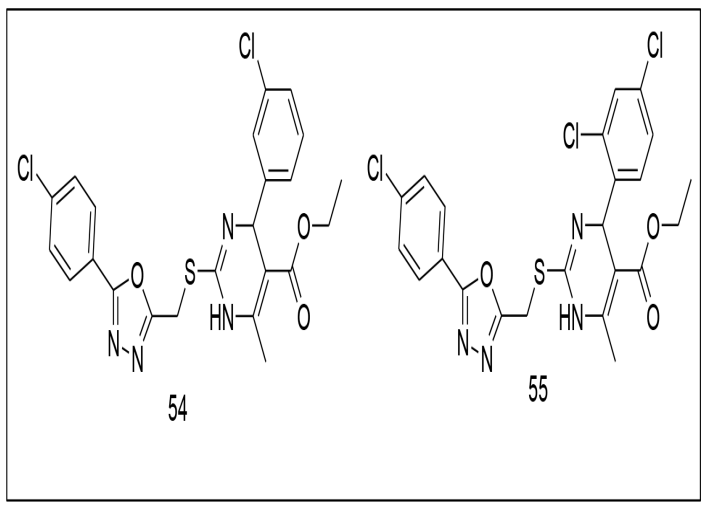

Figure 49: Chemical structure of compounds 54, 55 .

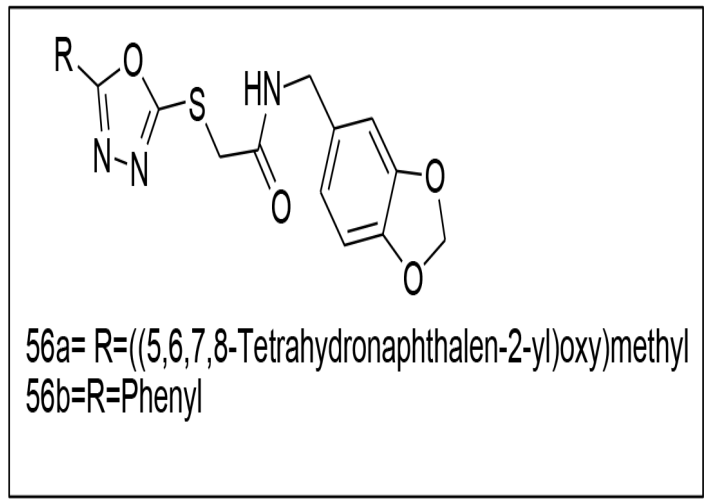

Figure 50: Chemical structure of compounds 56(a-b).

evaluation was done at the NCI, USA. It was indicated by the results that compound 57 (Figure 51) as potent compound with broad spectrum of activities on cell lines.

\section{Calcium channel blocker}

Girish R. Bankara et al. tested whether the correction of endothelial dysfunction is dependent on the normalization of high blood pressure levels by synthesized 1,3,4-oxadiazole derivative (compound 58) (Figure 52) (NOX-1) in deoxycorticosterone acetate and NG-nitro-1arginine hypertensive rats. ${ }^{54}$ In DOCA-salt and L-NNA hypertensive rats, the mean systolic blood pressure was 185.3 \pm 4.7 and $170.2 \pm 4.1 \mathrm{mmHg}$, whereas after administration of NOX-1 to hypertensive rats, MSBB was $127.8 \pm 4.5$ and $120.2 \pm 5.1 \mathrm{mmHg}$, respectively.

\section{Insecticidal activity}

Cao S et al. performed the synthesis of 2-(5-(Trifluoromethyl)pyridyloxylmethyl)-5-aryl-1,3,4-oxadiazole derivatives. ${ }^{55}$ All derivatives showed good insecticidal activity especially those bearing fluorine on the benzene ring, 59 (a-b) (Figure 53) demonstrated better insecticidal activity. 


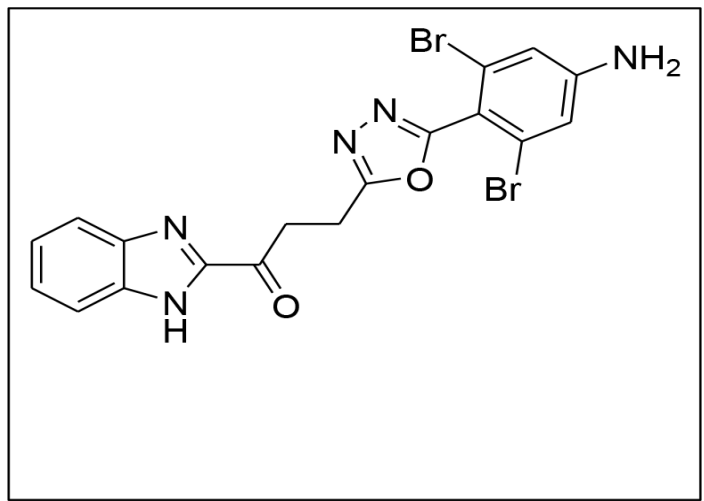

Figure 51: Chemical structure of compound 57.

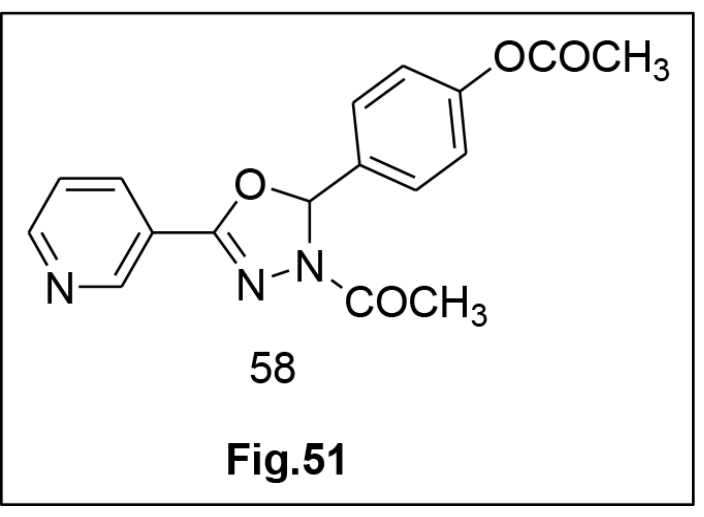

Figure 52: Chemical structure of compound 58.

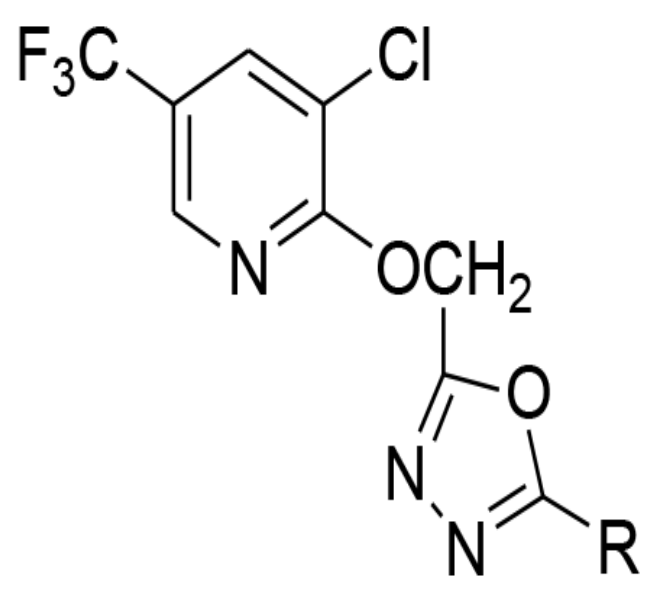

\section{$59 \mathrm{a}=\mathrm{R}=4-\mathrm{FC}_{6} \mathrm{H}_{4}$ $59 \mathrm{~b}=\mathrm{R}=2-\mathrm{FC}_{6} \mathrm{H}_{4}$}

Figure 53: Chemical structure of compounds 59(a-b).

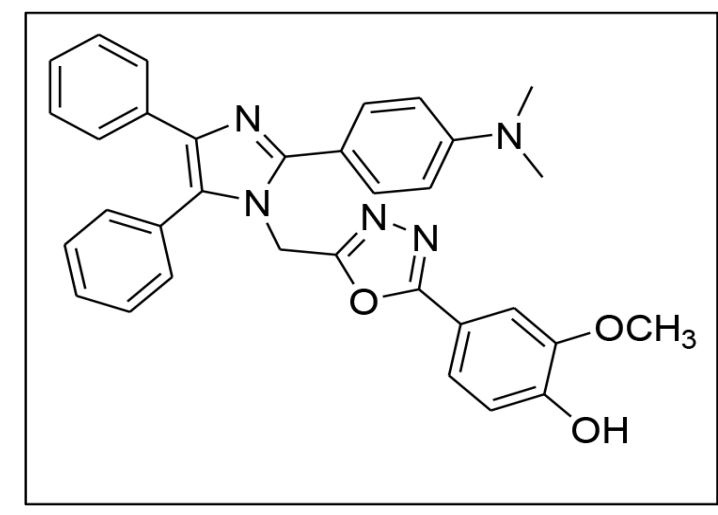

Figure 54: Chemical structure of compound 60.

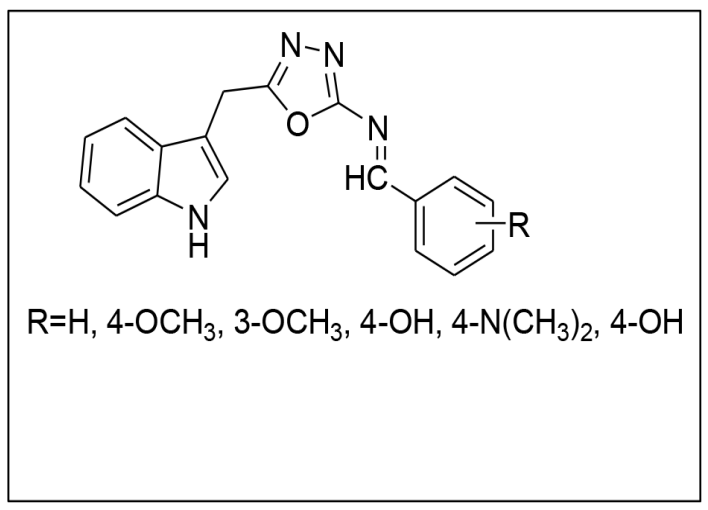

Figure 55: Chemical structure of compound 61.

\section{Cardiovascular activity}

Vineet Malhotra et al. synthesized a new series of novel substituted imidazole analogs and tested it for their hypotensive and acute toxicity activities. ${ }^{56}$ Eight compounds among the synthesized hits have shown good hypotensive and bradycardiac responses. Compound 60 (Figure 54) have shown potent activity than standard drug clonidine.

Navneet Singh et al. have presented the review showing the cardiovascular activity of Indole derivatives by incorporating Oxadiazole motif at 3- position of Indole, compound 61 (Figure 55). ${ }^{57}$ Various factors i.e. the change in blood pressure, heart rate, effect on Carotid Occlusion and Nordaniline pressor responses were observed for the cardiovascular study.

\section{MAO-Inhibitors}

Elias Maccioni et al. designed and synthesized 3-Acetyl-2,5-diaryl-2,3-dihydro-1,3,4-oxadiazoles derivatives 62 (a-f) (Figure 56) and evaluated as inhibitors of human monoamine oxidase $\mathrm{A}$ and $\mathrm{B}$ isoform. ${ }^{58}$ It was concluded that these prepared analogs were promising reversible and selective MAO-B inhibitors. Docking study was also performed. 


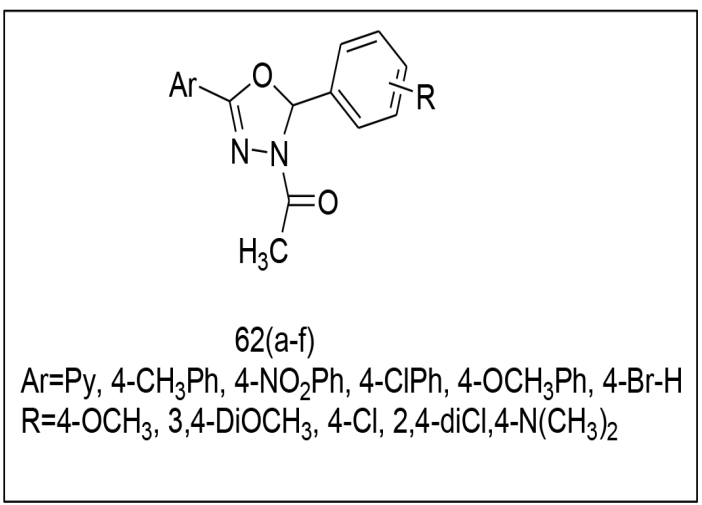

Figure 56: Chemical structure of compound 62(a-f).

\section{ACKNOWLEDGEMENT}

Authors are thankful to Delhi Institute of Pharmaceutical Sciences and Research, New Delhi, India for providing facilities for literature work. Two authors (Rubina Bhutani and Garima Kapoor) are also grateful to DST, India for financial support.

\section{CONFLICT OF INTEREST}

The authors declare no conflict of interest.

\section{ABBREVIATIONS}

MAO: Monoamine Oxidase; NCI: National Cancer Institute; DST: Department of Science and Technology; GSK: Glycogen Synthase Kinase; $\mu \mathbf{M}$ : Micromolar; $\mu$ : Alpha; DPPH: 2,2-Diphenyl-1-picrylhydrazyl; PTZ: Pentylene Tetrazole; MES: Maximal Electric Seizure; TMV: Tobacco Mosaic Virus; SAR: Structure Activity Relationship; DST: Department of Science and Technology.

\section{REFERENCES}

1. Boström J, Hogner A, Llinas A, Wellner E, Plowright AT. Oxadiazoles in medicinal chemistry. J Med Chem. 2012;55(5):1817-30.

2. Musmade DS, Pattan SR, Yalgatti MS. Oxadiazole a nucleus with versatile biological behavior. IJPC. 2015;05(01):11-20.

3. Singh AK, Sahu VK, Yadav D. Biological activities of 2, 5-disubstituted-1,3,4oxadiazoles. IJPSR. 2011;2(6):135-47.

4. Bhutani R, Pathak DP, Kapoor G, Husain A, Kant R, Iqbal MA. Synthesis, molecular modelling studies and ADME prediction of benzothiazole clubbed oxadiazole-Mannich bases and evaluation of their anti-diabetic activity through in vivo model. Bioorg Chem. 2018;77:6-15.

5. Srinivas S, Aparna V. Design, Synthesis, biological evaluation and molecular

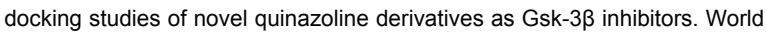
J Pharm Sci. 2013;2(6):5842-51.

6. Selvaraj K, Kulanthai K, Sadhasivam G. Synthesis, Characterization and Biological Evaluation of Novel 2,5 Substituted-1,3,4 Oxadiazole Derivatives. Saudi Pharm J. 2016;25(3):337-45.

7. Iqbal MAK, Khan AY, Kalashetti MB, Belavagi NS, Gong YD, Khazi IAM. Synthesis, hypoglycemic and hypolipidemic activities of novel thiazolidinedione derivatives containing thiazole/triazole/oxadiazole ring. Eur J Med Chem. 2012;53:308-15.
8. Shingalapur RV, Hosamani KM, Keri RS, Hugar MH. Derivatives of benzimidazole pharmacophore: Synthesis, anticonvulsant, antidiabetic and DNA cleavage studies. Eur J Med Chem. 2010;45(5):1753-59.

9. Kun S, Nagy GZ, Tóth M, Czecze L, Nhien ANV, Docsa T, et al. Synthesis of variously coupled conjugates of D-glucose, 1,3,4-oxadiazole and 1,2,3-triazole for inhibition of glycogen phosphorylase. Carbohydrate Research. 2011;346(12):1427-38.

10. Taher P, Hitesh P, Santilal P, Sangita S. Synthesis and antibacterial activity of novel benzothiazole based 1,3,4-oxadiazole derivatives. Inventi J. 2016;(1):1-26.

11. Jignesh PR, Tarunkumar NA, Dhavel MJ, Kruti NM, Nilesh HP. Synthesis and in vitro antibacterial activity of new oxoethylthio-1,3,4-oxadiazole derivatives. JSaud Chem Soci. 2014;18(2):101-6.

12. Kouhkan M, Karimi F, Souldozi A, Rashedi J. In vitro antimicrobial activity of new substituted 1,3,4-oxadiazole derivatives. Int J Adv Res. 2017;5(5):1468-74.

13. Khalilullah H, Khan SM, Nomani S, Ahmed B. Synthesis, characterization and antimicrobial activity of benzodioxane ring containing 1,3,4-oxadiazole derivatives. Arabian Journal of Chemistry. 2016;9(2):S1029-35.

14. Salahuddin, Shaharyar M, Mazumder A, Abdullah MM. Synthesis, characterization and antimicrobial activity of 1,3,4-oxadiazole bearing $1 \mathrm{H}$ benzimidazole derivatives. Arabian Journal of Chemistry. 2017;10(1):S503-08.

15. Gollapalli NR, Tadikonda GP, Peruru L, Surepalli JM, Rama RN. Synthesis, characterization and biological activity of some 1,3,4-oxadiazole derivatives with benzothiazole moiety. Der Pharmacia Sinica. 2015;6(6):1-8.

16. Chawla G, Kumar U, Bawa S, Kumar J. Synthesis and evaluation of antiinflammatory, analgesic and ulcerogenic activities of 1,3,4- oxadiazole and 1,2,4-triazolo[3,4-b]-1,3,4-thiadiazole derivatives. J Enzyme Inhib Med Chem. 2012;27(5):658-65.

17. Durgashivaprasad E, Mathew G, Sebastian S, Reddy MSA, Mudgal J, Nampurath GK. Novel 2,5-disubstituted-1,3,4-oxadiazoles as antiinflammatory drugs. Indian J Pharmacol. 2014;46(5):521-26.

18. Almasirad A, Mousavi Z, Tajik M, Assarzadeh MJ, Shafiee A. Synthesis, analgesic and anti-inflammatory activities of new methyl-imidazolyl-1,3,4oxadiazoles and 1,2,4-triazoles. DARU J Pharm Sci. 2014;22(1):1-8.

19. Kumar V, Sharma S, Husain A. Synthesis and in vivo anti-inflammatory and analgesic activities of oxadiazoles clubbed with benzothiazole nucleus. ICPJ. 2015;4(12):457-61.

20. Abd-Ellah HS, Aziz MA, Shoman ME, Beshr EAM, Kaoud TS, Ahmed AFF. Novel 1,3,4-oxadiazole/oxime hybrids: Synthesis, docking studies and investigation of anti-inflammatory, ulcerogenic liability and analgesic activities. Bioorg Chem. 2016;69:48-63.

21. Akhter M, Husain A, Azad B, Ajmal M. Aroylpropionic acid based 2,5-disubstituted-1,3,4-oxadiazoles: Synthesis and their anti-inflammatory and analgesic activities. Eur J Med Chem. 2009;44(6):2372-8.

22. Ahsan MJ, Samy JG, Khalilullah H, Nomani MS, Saraswat P, Gaur R, et al. Molecular properties prediction and synthesis of novel 1,3,4-oxadiazole analogues as potent antimicrobial and antitubercular agents. Bioorg Med Chem Lett. 2011;21(24):7246-50.

23. Chandrasekera NS, Bailey MA, Files M, Alling T, Florio SK, Ollinger J, et al. Synthesis and anti-tubercular activity of 3-substituted benzo[b]thiophene-1,1dioxides. Peer J. 2014. https://doi.org/10.7717/peerj: 612; PMid:25320680

24. Karabanovich G, Zemanová J, Smutný T, Székely R, Šarkan M, Centárová I, et al. Development of 3,5-dinitrobenzylsulfanyl-1,3,4-Oxadiazoles and thiadiazoles as selective antitubercular agents active against replicating and nonreplicating mycobacterium tuberculosis. J Med Chem. 2016;59(6):2362-80.

25. Kumar GVS, Rajendraprasad Y, Mallikarjuna BP, Chandrashekar SM, Kistayya C. Synthesis of some novel 2-substituted-5-[isopropylthiazole] clubbed 1,2,4-triazole and 1,3,4-oxadiazoles as potential antimicrobial and antitubercular agents. Eur J Med Chem. 2010;45(5):2063-74.

26. Ladania GG, Patel MP. Novel 1,3,4-oxadiazole motifs bearing quinoline nucleus: synthesis, characterization and their biological evaluation for antimicrobial, antitubercular, antimalarial and cytotoxic activity. New J Chem. 2015;39(12):9848-57.

27. Attaby FA, Fattah AMA, Shaif LM, Elsayed MM. Anti-alzheimer and anti-cox-2 activities of the newly synthesized 2,3-bipyridine derivatives (ii). Phosphorus Sulfur Silicon Relat Elem. 2010;185(3):668-79.

28. Kamal A, Shaik AB, Reddy GN, Kumar CG, Joseph J, Kumar GB, et al. Synthesis, biological evaluation and molecular modeling of (E)-2-aryl-5- 
styryl-1,3,4-oxadiazole derivatives as acetylcholine esterase inhibitors. Med Chem Res.2014;23(4):2080-92.

29. Saitoh M, Kunitomo J, Kimura E, Hayase Y, Kobayashi H. Design, synthesis and structure-activity relationships of $1,3,4$-oxadiazole derivatives as novel inhibitors of glycogen synthase kinase-3 $\beta$. Bioorg Med Chem. 2009;17(5):2017-29.

30. Shridhar AH, Keshavayya J, Peethambar SK, Hoskeri HJ. Synthesis and biological activities of Bis alkyl 1,3,4-oxadiazole incorporated azo dye derivatives. Arabian Journal of Chemistry. 2016;9:S1643-48.

31. Abdelmonem YK, El-Essawy FA, El-Enein SAA, El-Sheikh-Amer MM. Docking studies, synthesis and evaluation of antioxidant activities of N-Alkylated, 1, 2, 4-Triazole, 1, 3, 4-Oxadiazole and thiadiazole containing the aminopyrazolopyridine derivatives. Int J Org Chem.2013;3(3):198-205.

32. Patrao P, Khadera AMA, Kalluraya B, Vinayachandra, Synthesis of new 5-naphthyl substituted 1,3,4-oxadiazole derivatives and their antioxidant activity. Der Pharma Chemica. 2013;5(2):24-32.

33. Mohana KN, Kumar CBP. Synthesis and antioxidant activity of 2-Amino-5methylthiazol derivatives containing 1,3,4-Oxadiazole-2-thiol moiety. ISRN Organic Chemistry. 2013. http://dx.doi.org/10.1155/2013/620718.

34. Sindhe MA, Yadav DB, Telkar S, Chandrashekar A. Synthesis of a series of novel 2,5-disubstituted-1,3,4-oxadiazole derivatives as potential antioxidant and antibacterial agents. J Chem Biol. 2016;9(3):79-90.

35. Mihailovic N, Markovic V, Matic IZ, Stanisavljevic NS, Jovanovic ZS, Trifunovic $S$, et al. Synthesis and antioxidant activity of 1,3,4-oxadiazoles and their diacylhydrazine precursors derived from phenolic acids. RSC Adv. 2017;14(7):8550-60.

36. Bharatiya N, Gharu CP. Green and efficient microwave one pot synthetic approach to N-Phenyl Piperazinyl-1,3,4-Oxadiazole derivatives and evaluation of their Antioxidant and Anti Inflammatory Activity. IJAR. 2014;4(11):88-90.

37. Vaishali, Ahmed B. Synthesis, docking Analysis and anticonvulsant activity of substituted hydrazone and 1,3,4-Oxadiazole derivatives. J Chem Pharm Res. 2017;9(5):364-70.

38. Shaharyar M, Akhter MW. Synthesis and anticonvulsant activity of substituted oxadiazole and thiadiazole derivatives. ActaPol Pharm Drug Research. 2009;66(4):393-7.

39. Rajak H, Singour P, Kharya MD, Mishra P. A Novel Series of 2,5-Disubstituted 1,3,4-oxadiazoles: Synthesis and SAR Study for their Anticonvulsant Activity. Chem Biol Drug Des. 2011;77(2):152-8.

40. Tabatabaia SA, Lashkaric SB, Zarrindastc RM, Gholibeikiand M, Shafieee A. Design, Synthesis and Anticonvulsant Activity of 2-(2-Phenoxy) phenyl1,3,4oxadiazole Derivatives. IJPR. 2013;12(Suppl):105-11.

41. Bhat MA, Al-Omar MA, Siddiqui N. Synthesis, anticonvulsant and neurotoxicity of some novel 1,3,4-oxadiazole derivatives of phthalimide. Der Pharma Chemica. 2010;2(2):1-10.

42. Gilani SJ, Alam O, Khan SA, Siddiqui N, Kumar H. Synthesis of some derived thiazolidin-4-one, azetidin-2-one and 1,3,4-oxadiazole ring systems from Isoninicotinic acid hydrazide: A novel class of potential anticonvulsant agents. Der Pharmacia Lettre. 2009;1(2):1-8.

43. El-Sayed WA, El-Essawy FA, Ali OM, Nasr BS, Abdalla MM, AbdelRahman AAH. Synthesis and antiviral evaluation of new 2,5-disubstituted 1,3,4-oxadiazole derivatives and their acyclic nucleoside analogues. Monatsh Chem. 2010;141(9):1021-8.

44. Wu W, Chen Q, Tai A, Jiang G, Ouyang G. Synthesis and Antiviral Activity of 2-substitutedmethylthio-5-(4-amino-2-methylpyrimidin-5-yl)-1,3,4-oxadiazole derivatives. Bioorg Med ChemLett. 2015;25(10):2243-6.
45. Dong L, Song B, Wu J, Wu Z, Zhu Y, Chen X, et al. Synthesis and antiviral activity of novel thioether derivatives containing 1,3,4-oxadiazole/ thiadiazole and emodin moieties. Phosphorus Sulfur Silicon Relat Elem. 2016;191(6):904-7. http://dx.doi.org/10.1080/10426507.2015.1114944.

46. Gan X, Hu D, Li P, Wu J, Chen X, Xue W, et al. Design, synthesis, antiviral Activity and 3D-QSAR Study of Novel 1,4-Pentadien-3-one derivatives containing the1,3,4-oxadiazole Moiety. Pest Management Science. 2016;72(3):534-43. http://dx.doi.org/10.1002/ps.4018; PMid:25847602.

47. Gan X, Hu D, Chen Z, Wang Y, Song B. Synthesis and antiviral evaluation of novel 1,3,4-oxadiazole/thiadiazolechalcone conjugates. Bioorg Med Chem Lett. 2017;27(18):4298-301.

48. Salahuddin, Mazumder A, Shaharyar M. Synthesis, characterization and In vitro anticancer evaluation of novel 2,5-Disubstituted 1,3,4-oxadiazole analogue. Bio Med Research International. 2014. http://dx.doi. org/10.1155/2014/491492.

49. Ahsan MJ, Shastri S, Yadav R, Hassan MZ, Bakht MA, Jadav SS, et al . Synthesis and Antiproliferative Activity of Some Quinoline and Oxadiazole Derivatives. Organic Chemistry International. 2016. http://dx.doi. org/10.1155/2016/9589517.

50. Gu W, Jin XY, Li DD, Wang SF, Tao XB, Chen H. Design, synthesis and in vitro anticancer activity of novel quinoline and oxadiazole derivatives of ursolic acid. Bioorganic and Medicinal Chemistry Letters. 2017;27(17):4128-32. http://dx.doi. org/10.1016/j.bmcl.2017.07.033; PMid: 28733083.

51. Ragab FAF, Abou-Seri SM, Abdel-Aziz S.A, Alfayomy AM, Aboelmagd $M$. Design, synthesis and anticancer activity of new monastrol analogues bearing 1,3,4-oxadiazole moiety. European Journal of Medicinal Chemistry. 2017;138:140-51. https://doi.org/10.1016/j.ejmech.2017.06.026; PMid: 28667871.

52. Özdemir A, Sever B, Altıntop MD, Temel HE, Atlı O, Baysal M,et al. Synthesis and evaluation of new oxadiazole, thiadiazole and triazole derivatives as potential anticancer agents targeting MMP-9. Molecules. 2017;22(1109):1-15.

53. Husain A, Rashid M, Mishra R, Parveen S, Shin D, Kumar D. Benzimidazole bearing oxadiazole and triazolo-thiadiazoles nucleus: Design and synthesis as anticancer agents. Bioorganic Med Chem Lett. 2012;22(17):5438-44.

54. Bankara GR, Nampuratha GK, Nayaka PG, Bhattacharya S. A possible correlation between the correction of endothelial dysfunction and normalization of high blood pressure levels by 1,3,4-oxadiazole derivative, an L-type Ca2+ channel blocker in deoxycorticosterone acetate and NG-nitro-Iarginine hypertensive rats. Chem Biol Interact. 2010;183(2):327-31.

55. Cao S, Qian X, Song G, Huang Q. Synthesis and insecticidal activity of new 2-(5-(trifluoromethyl) pyridyloxymethyl)-1, 3, 4-oxadiazoles. J Fluor Chem. 2002;117(1):63-6.

56. Malhotra V, Pathak SR, Nath R, Mukherjee D, Shanker K. Substituted imidazole derivatives as novel cardiovascular agents. Bioorg Med Chem Lett. 2011;21(3):936-9.

57. Singh N, Aggarwal RC, Singh CP. Cardiovascular activity of Indole derivatives by incorporating Oxadiazole, Azetidinone and Thiazolidinone Moieties: A Review. Int J Drug Dev and Res. 2014;6(1):30-9.

58. Maccioni BE, Alcaro S, Cirilli R, Vigo S, Cardia MC, Sanna ML, et al. 3-Acetyl2,5-diaryl-2,3-dihydro-1,3,4-oxadiazoles: A New Scaffold for the Selective Inhibition of Monoamine Oxidase. J Med Chem. 2011;54(18):6394-98. 
PICTORIAL ABSTRACT

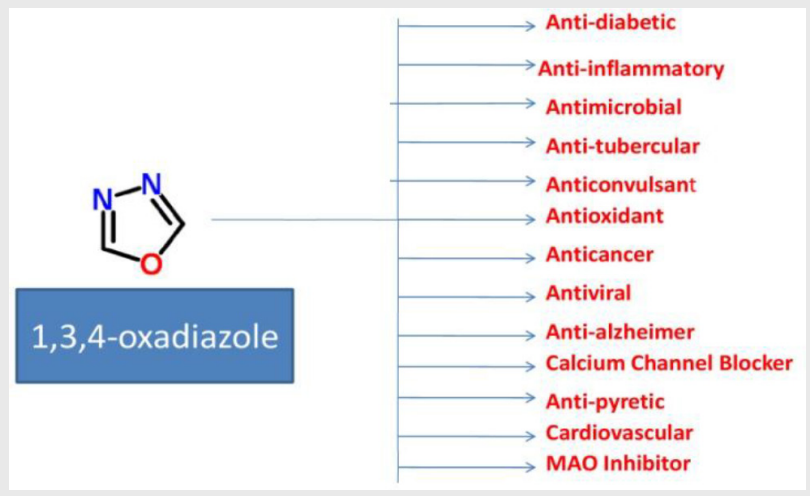

\section{SUMMARY}

- Five membered nitrogen-oxygen containing heterocyclic core, Oxadiazole is a vital scaffold in medicinal chemistry.

- 1,3,4-oxadiazole and its derivatives showed wide range of biological potential such as anti-diabetic, anti-cancer, anti-bacterial etc.

- This review emphasizes on current updates on biological profile of 1,3,4-oxadiazole based compounds.

- Thus 1,3,4-oxadiazole scaffold can be further explored for development of potent medicinal agents.

Cite this article: Rubina B, Dharam PP, Garima K, Ravi K, Manni D. Recent Developments on Pharmacological Potential of 1,3,4-Oxadiazole Scaffold. Indian J of Pharmaceutical Education and Research. 2019;53(2S):s1-s16. 